\title{
INTEGRATING NITROGEN SOURCE AND APPLICATION TIMING INTO THE MANAGEMENT OF LARGE PATCH ON ZOYSIAGRASS
}

A Thesis
presented to
the Faculty of the Graduate School
at the University of Missouri-Columbia
In Partial Fulfillment
of the Requirements for the Degree
MASTER OF SCIENCE
by
JOHN F. KOEHELR
Dr. Gerald L. Miller, Thesis Supervisor


The undersigned, appointed by the dean of the Graduate School, have examined the thesis entitled

INTEGRATING NITROGEN SOURCE AND APPLICATION TIMING INTO THE MANAGEMENT OF LARGE PATCH ON ZOYSIAGRASS

presented by John F. Koehler, a candidate for the degree of Master of Science, and hereby certify that, in their opinion, it is worthy of acceptance.

Gerald Miller

Associate Professor-Division of Plant Sciences

(Advisor and Committee Chair)

Brad Fresenburg

Assistant Extension Professor-Division of Plant Sciences (Committee Member)

Jeanne Mihail

Professor-Division of Plant Sciences

(Committee Member)

Peter Motavalli

Professor-School of Natural Resources

(Committee Member) 


\section{DEDICATION}

This thesis is dedicated to my parents, Helen and Mike. Thank you for your constant love and support and for always encouraging me in everything I do. 


\section{ACKNOWLEDGEMENTS}

I would first like to thank my family, Emma, Clare, Mark, Luke, and my parents, Helen and Michael, for their constant encouragement. I would also like to thank my friends, fellow graduate students, and professors at the University of Missouri for their support. I am especially grateful to my advisor, Dr. Lee Miller, for giving me this opportunity and for always encouraging me to be a better researcher. Thank you to my committee members, Dr. Brad Fresenburg, Dr. Jeanne Mihail, and Dr. Peter Motavalli. Finally, I want to thank Daniel Earlywine, Kyle Robertson, Clayton Rushford, and Marilyn Bonham for their assistance and support throughout this process. 


\section{TABLE OF CONTENTS}

ACKNOWLEDGEMENTS ...ii

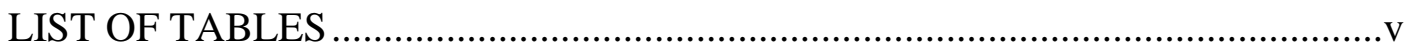

LIST OF FIGURES …..........................................................................

ABSTRACT ....................................................................................................

CHAPTER 1: INTRODUCTION AND LITERATURE REVIEW ........................

Turfgrass Usage in Missouri .................................................................2

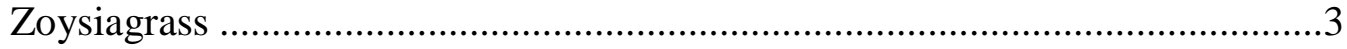

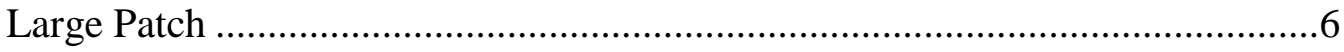

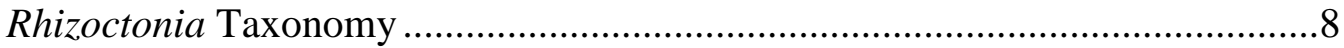

Penetration and Infection of Rhizoctonia ......................................................10

Fungal Melanin and Its Role in Infection ..................................................11

Nitrogen and Rhizoctonia Disease Severity.................................................. 14

Impact of Nitrogen on Turfgrass Diseases................................................ 15

Chemical Management of Large Patch ........................................................ 18

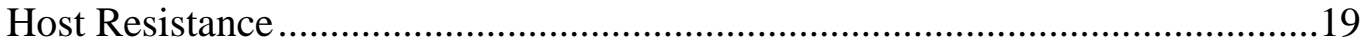

Cultural Management Practices ................................................................220

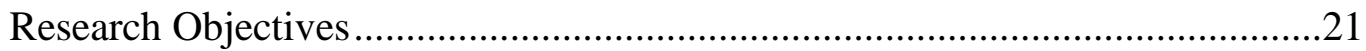

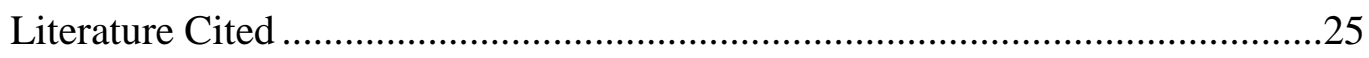

CHAPTER 2: Impact of nitrogen source and a $\mathrm{pH}$ buffer on the in vitro growth and morphology of Rhizoctonia solani AG 2-2 LP .......................................................32

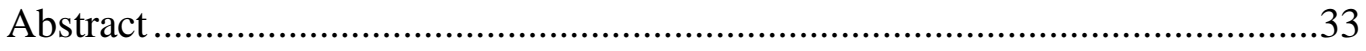

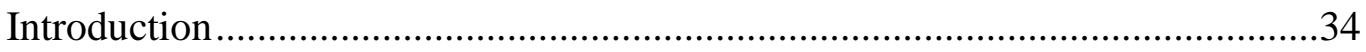

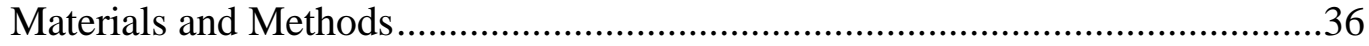

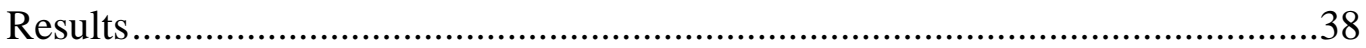


Discussion

Literature Cited

CHAPTER 3: Impact of nitrogen application timing, nitrogen source, and a single fungicide application on large patch of zoysiagrass

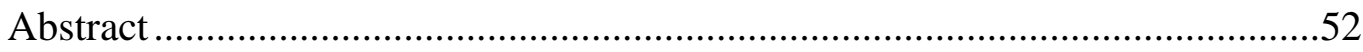

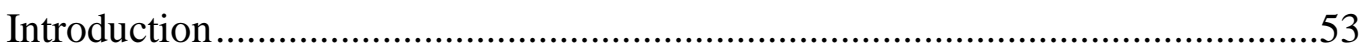

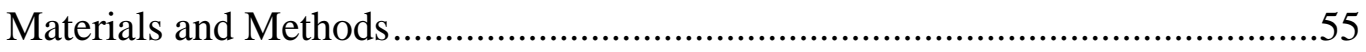

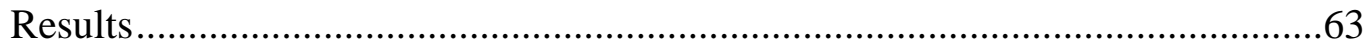

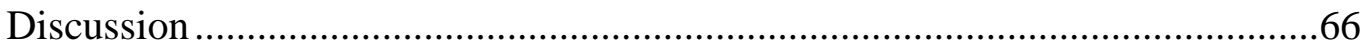

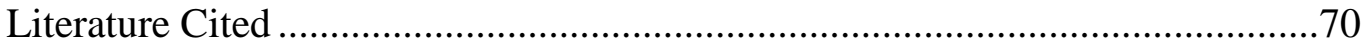




\section{LIST OF TABLES}

Tables

Page

2.1 Nitrogen media pHs after autoclaving and after 7-days growth of isolates 45

2.2 Gray scale values of Rhizoctonia solani AG 2-2 LP isolates 46

2.3 Gray scale pigmentation of Rhizoctonia solani AG 2-2 LP isolates 47

3.1 Application dates for fall, spring, and summer nitrogen treatments .................... 73

3.2 Effects of growth media on infection potential of $R$. solani AG 2-2 LP ............... 74

3.3 Effects of nitrogen fertility source and inoculum type on the quality and disease severity on zoysiagrass in a growth chamber ................................................... 75

3.4 Effects of nitrogen source, application timing, and a single fungicide application on large patch of zoysiagrass..................................................................... 76

3.5 Effect of nitrogen source on large patch severity …...................................... 77

3.6 Effect of nitrogen source on turfgrass quality........................................... 78 


\section{LIST OF FIGURES}

Figures

Page

2.1 Radial large patch isolate growth on a non-buffered basal medium amended with calcium nitrate, ammonium sulfate, or urea

2.2 Radial large patch isolate growth on a basal medium buffered with $200 \mu \mathrm{g} \mathrm{ml}^{-1}$ fumaric acid $\mathrm{pH}$ buffer and amended with either calcium nitrate, ammonium sulfate, or urea.

2.3 Morphology of $R$. solani AG 2-2 LP on different nitrogen media with and without fumaric acid buffer 50

3.1 Disease severity of zoysiagrass in a controlled environment after nitrogen fertility applications

3.2 Regression analysis of AUDPC vs AUNGCC 80

3.3 Effects of nitrogen application timing on non-green turf in Spring 2015. 81

3.4 Effects of nitrogen application timing on non-green turf in Spring 2016. 82

3.5 Effects of nitrogen application timing on non-green turf in Fall 2016 83

3.6 Effects of nitrogen application timing on non-green turf in Spring 2017. 84

3.7 Effects of nitrogen application timing on visual large patch severity on zoysiagrass in Spring 2015

3.8 Effects of nitrogen application timing on visual large patch severity on zoysiagrass in Spring 2016. 86

3.9 Effects of nitrogen application timing on visual large patch severity on zoysiagrass in Fall 2016.

3.10 Effects of nitrogen application timing on visual large patch severity on zoysiagrass in Spring 2017 


\begin{abstract}
Large patch is the most limiting disease that affects zoysiagrass in the upper transition zone of the United States. Management of this disease requires two to four fungicide applications split between the fall and spring disease periods. Limited research has been conducted to determine the effects of cultural practices on large patch disease outbreaks, specifically related to nitrogen applications. The first goal of this research was to evaluate nitrogen source impacts on the growth, morphology, and infection potential of the causal pathogen Rhizoctonia solani AG 2-2 LP. The second goal was to determine how specific nitrogen application timings, nitrogen source, and a single fungicide application impact disease severity. In the laboratory, pathogen growth was highest on calcium nitrate-amended media compared to both ammonium sulfate and urea media. Pathogen pigmentation was dark brown on high concentrations of calcium nitrate and urea media, but was white on high concentrations of ammonium sulfate media with and without a $\mathrm{pH}$ buffer. Nitrogen source did not impact pathogen infection on zoysiagrass tillers in a greenhouse experiment. In the field, summer nitrogen applications without tebuconazole had the highest disease severity in all seasons of the study. Spring and/or fall nitrogen applications did not increase large patch severity, and spring fertility was most consistent with decreased large patch severity. Similar to the greenhouse, nitrogen source did not impact disease severity in the field. A single spring tebuconazole application was effective at reducing large patch severity, but not in preventing initial disease incidence. When planning for large patch management, spring nitrogen and tebuconazole applied prior to $18^{\circ} \mathrm{C} 5$-cm soil temperatures would be most beneficial in reducing disease severity.
\end{abstract}




\section{Chapter 1}

Introduction and Literature Review 


\section{INTRODUCTION}

Large patch is the most limiting disease on zoysiagrass (Zoysia japonica Steud.) in the United States transition zone (Smiley et al. 2005). This disease is caused by the pathogen Rhizoctonia solani AG 2-2 LP, which infects zoysiagrass in the fall and spring months when zoysiagrass growth slows as it enters and exits cold-weather dormancy (Hyakumachi et al. 1998; Smiley et al. 2005). Symptoms appear as circular matted areas of brown or orange turf, and individual plants can experience basal sheath rot in the advanced stages of the disease (Couch 2000).

Zoysiagrass is favored for use in the transition zone due to its good cold tolerance, low maintenance requirements, and excellent quality during the hot summer months (Fry et al. 2008). However, large patch is consistently an issue on golf course fairways and tees as well as home lawns, and can require two to four chemical applications per year to control (Miller et al. 2016). Reducing the need for multiple chemical inputs by implementing better cultural practices would be both economically and environmentally beneficial. This research investigates the impact of nitrogen source on the large patch pathogen and attempts to integrate specific nitrogen fertility timing and source choice with chemical practices to better suppress large patch on zoysiagrass.

\section{Turfgrass Usage in Missouri}

The turfgrass industry in Missouri provides approximately 20,000 jobs and an estimated $\$ 1.3$ billion contribution to the economy (Missouri Valley Turfgrass Association 1999). Of the 607,000 total hectares of turfgrass in Missouri, residential lawns cover approximately 324,000 hectares and golf courses cover 16,000 hectares. Home lawns account for nine out of ten dollars spent on turfgrass-related products and 
services. In 2010, the size of the Missouri golf industry economy was $\$ 888.6$ million. This industry has a total economic impact of $\$ 1.7$ billion dollars in the state of Missouri, supports nearly 21,000 jobs and provides a total wage income of $\$ 485.1$ million (Missouri Valley Turfgrass Association 1999; SRI International 2011).

Missouri is located in the climactic transition zone of the United States. This region covers 480 to 1130 kilometers from Kansas to Maryland and lies between the cool, humid northern region and the warm, humid southern region (Christians 2007; Dunn and Diesburg 2004). In Missouri, the average January temperatures range between $-11^{\circ} \mathrm{C}$ in the northwest to $-4^{\circ} \mathrm{C}$ in the southeast, while the mean July temperature for the state is between 30 and $32^{\circ} \mathrm{C}$. Although cool- and warm-season grasses are adapted best for the northern and southern regions respectively, neither type is completely adapted to the extremes of the transition zone climate. Several members of the Poaceae family are utilized as turfgrasses in the transition zone, including cool-season grasses such as Kentucky bluegrass (Poa pratensis L.), perennial ryegrass (Lolium perenne L.), tall fescue (Festuca arundinacea Schreb.), bentgrasses (Agrostis spp L.), and warm-season grasses such as buffalograss (Buchloë dactyloides (Nuft.) Englem.), bermudagrass (Cynodon dactylon (L.) Pers. ), and zoysiagrass (Zoysia spp. Willd) (Christians 2007; Dunn and Diesburg 2004).

\section{Zoysiagrass}

Zoysiagrass is a popular species of warm-season turfgrass for lawns, golf course fairways and tees throughout Missouri and the transition zone. Morphologically, zoysiagrass has a rolled vernation, no auricles, and pubescence on the leaf blades, the fringe of the ligule, and on the broad, continuous collar (Christians 2007). It is 
rhizomatous and stoloniferous, and the stolon nodes are covered with a tan husk.

Zoysiagrass is known for its stiff, tough leaf blades, which provide a high-quality playing surface that can withstand wear and high traffic (Dunn and Diesburg 2004). Although some cultivars of zoysia yield viable seed, germination and establishment from seed is often slow and poor. Therefore, establishment is most often accomplished through sprigging, plugging, sodding, or strip sodding (Christians 2007). Compared to coolseason turfgrasses, zoysiagrass is relatively free from insect damage and disease, and the dense turf excludes weeds. Shade tolerance for zoysiagrass is fair, it is relatively salt tolerant, and it holds up well in droughty conditions (Christians 2007; Dunn and Diesburg 2004).

Warm-season turfgrasses, including zoysiagrass, utilize $\mathrm{C}_{4}$ photosynthesis. Coolseason turfgrasses, such as creeping bentgrass (Agrostis stolonifera L.), belong to the $\mathrm{C}_{3}$ photosynthesizing grasses. $\mathrm{C}_{4}$ grasses produce a four-carbon intermediate during photosynthesis and grow best between 29 and $35^{\circ} \mathrm{C}$, while $\mathrm{C}_{3}$ grasses produce a threecarbon intermediate and grow best between 18 and $24^{\circ} \mathrm{C}$. At high temperatures, the RuBisCO enzyme is less likely to distinguish between $\mathrm{CO}_{2}$ and $\mathrm{O}_{2}$, making photosynthesis less efficient through a process called photorespiration. Unlike $\mathrm{C}_{3}$ plants which are prone to photorespiration, $\mathrm{C}_{4}$ plants separate $\mathrm{RuBisCO}$ fixation into bundle sheath cells where $\mathrm{O}_{2}$ concentrations are low, preventing this inefficiency at high temperatures. As a warm-season grass, zoysia growth declines in the fall and undergoes a period of winter dormancy beginning when soil temperatures drop to $10^{\circ} \mathrm{C}$. Coolseason grasses stay green throughout the fall and can even remain green during winter. 
In the early spring when soil temperatures rise to $10^{\circ} \mathrm{C}$, zoysiagrass begins to green up and reaches its peak growth in midsummer (Christians 2007).

Within the Zoysia genus, three species are used as turfgrass in the United States: Japanese lawngrass (Zoysia japonica Steud.), manilagrass (Zoysia matrella [L.] Merr.), and mascarenegrass (Zoysia pacifica [Goudswaard] Hotta \& Kuroki) formerly Z. tenuifolia Willd. (Christians 2007; Dunn and Diesburg 2004). Zoysia pacifica has the finest leaf texture of the three species and is intolerant of cold temperatures, making it unsuitable for transition zone winters. 'Emerald' zoysia is a Z. pacifica and Z. japonica hybrid that is commercially available in the United States (Christians 2007; Dunn and Diesburg 2004; Patton 2010). Zoysia matrella is coarser and more cold-tolerant than Z. pacifica (Patton and Reicher 2007). Compared to Z. japonica, Z. matrella has finer leaves and higher density. It is also more salt- and pest-tolerant than Z. japonica, but grows more slowly and is less cold tolerant (Patton 2010). 'Cashmere', 'Diamond', 'Cavalier', 'PristineFlora', 'Rollmaster', 'Royal', ‘Shadowturf', 'Zeon', and 'Zorro' are all varieties of Z. matrella that are used in the United States (Christians 2007; Patton 2010). Zoysia japonica is the most widely used species of zoysia in the United States, and it is the only species with seeded cultivars available (Patton 2010). Commercially available varieties of Z. japonica include 'Meyer', 'El Toro', 'Zenith' (seeded), ‘Carrizo', 'Compadre' (seeded), ‘Crowne', 'DeAnza', ‘Empire', ‘Empress', ‘GN-Z', 'Himeno’, 'JaMur', 'Marion', 'Palisades', 'Serene’, 'Southern Gem', 'UltimateFlora', 'Y2', 'ZoyBoy', and 'Belair' (Christians 2007; Dunn and Diesburg 2004; Patton 2010). 'Meyer' zoysiagrass, a vegetatively-propagated variety, is the most widely used zoysia variety on golf courses and lawns in the upper transition zone due to its excellent 
heat and drought tolerance and good winter hardiness (Dunn and Diesburg 2004; Fry et al. 2008). Compared to bermudagrass, the other major warm-season turfgrass utilized on transition zone fairways, 'Meyer' zoysiagrass is more tolerant of cold temperatures, making it better suited for the extreme transition zone winters (Dunn and Diesburg 2004). Zoysiagrass also requires less watering, mowing, fertilizer, and pesticide applications than cool-season species such as creeping bentgrass, another choice for transition zone fairways and tees (Fry et al. 2008). Creeping bentgrass is extremely stoloniferous, and requires more cultivation than the slower-growing zoysia to maintain high-quality turf. Since zoysia spreads through both stolons and rhizomes, it can recover more completely from high-traffic damage than creeping bentgrass. Warm-season grasses like zoysiagrass also have deeper root systems than cool-season grasses, allowing them to survive drought conditions more effectively. Unlike zoysiagrass, cool-season grasses undergo summer decline at high temperatures and their shallow root systems need constant replacement under high soil temperatures (Christians 2007). Weeds also encroach more easily on creeping bentgrass, and diseases such as brown patch, dollar spot, and Pythium blight are major problems on creeping bentgrass, requiring more fungicide inputs to maintain quality than zoysiagrass (Fry et al. 2008).

\section{Large Patch}

Although zoysia is favored for its durability, low maintenance, and pest tolerance, the species is susceptible to some insect and disease issues. Large patch, caused by the pathogen Rhizoctonia solani AG 2-2 LP, is the most significant disease that affects zoysiagrass in the transition zone (Hyakumachi et al. 1998; Smiley et al. 2005). Large patch symptoms appear as circular matted areas of brown or orange turf. Bright orange 
patch margins known as "firing" symptoms may also be observed in both spring and fall (Smiley et al. 2005). The patches range from 1 to 8 meters in diameter and expand rapidly in wet, cool weather. When active, large patch causes reddish-brown lesions on the leaf sheaths that can spread into the stem. Affected plants may rot at the base of the sheath, and are easily pulled from their stolons in advanced stages of the disease (Couch 2000). Large patch can be severe enough to leave rings or patches of almost completely killed turf, and recovery may be slow due to the slow growth of zoysia during the infection period (Dunn and Diesburg 2004; Smiley et al. 2005).

Large patch incidence occurs in early fall and spring when zoysiagrass is either going into or coming out of dormancy, with optimal infection temperatures between 20$25^{\circ} \mathrm{C}$ (Couch 2000; Smiley et al. 2005). During the fall, warm-season grasses begin to lose chlorophyll when the grass is entering dormancy, slowing down their metabolic rates. In the spring, the grass makes carbohydrates that were depleted during the winter to grow new leaves and roots. Due to the slowed zoysiagrass metabolism in the spring and fall, the plant is predisposed to $R$. solani infection and disease symptom development (Burpee and Martin 1996; Christians 2007). In the fall, symptoms are observed first as small light green patches, which can develop into large brown patches (Couch 1995). Patches appear again in the spring as the grass comes out of dormancy during green-up (Couch 2000). Large patch symptoms may recur in the spring usually in the same location from the previous fall (Couch 1995; Green II et al. 1993; Smiley et al. 2005). Isolates of $R$. solani AG 2-2 LP have been isolated from zoysiagrass tissue that is obviously not symptomatic, indicating this pathogen may be present but not active until environmental conditions favor pathogen growth (Aoyagi et al. 1998). 


\section{Rhizoctonia Taxonomy}

The causal agent of large patch is the basidiomycete fungi, Rhizoctonia solani Kühn, a ubiquitous fungus with numerous plant hosts (Armentrout and Downer 1987). Rhizoctonia are from the order Cantharellales and the family Ceratobasidiaceae. Fungi of the genus Rhizoctonia have hyphae 5 to $17 \mu \mathrm{m}$ in diameter without clamp connections, separated by a dolipore septum, constricted right-angle branching near the septum, and produce monilioid cells. The genus does not produce conidia, and survives saprophytically in organic matter (Smiley et al. 2005; Sneh et al. 1991; Stalpers and Andersen 1996). Rhizoctonia may also form sclerotia-like structures called bulbils during unfavorable environmental conditions or when deprived of nutrients (Christias and Lockwood 1973; Smiley et al. 2005; Vargas 2005). The bulbils are 1 to $3 \mathrm{~mm}$ diameter loose masses of mycelia that are a dark brown to black color and are not differentiated into a medulla and rind, a usual characteristic of bulbils produced by other fungal genera (Smiley et al. 2005; Sumner 1996; Townsend and Willetts 1954).

Rhizoctonia spp. can be differentiated by mycelial color, number of nuclei, and teleomorph morphology. Within the genus, the multinucleate Rhizoctonia solani is the most studied species (Sneh et al. 1991). The sexually reproducing teleomorph of $R$. solani is Thanatephorus cucumeris Donk, which forms 10-25 x 6-19 $\mu$ m hyaline basidia that are barrel-shaped to subcylindrical (Burpee and Martin 1992; Parmeter 1970; Smiley and Cook 1973). Sterigmata of the basidia are stout, usually straight, and have a broad base (Parmeter 1970; Stalpers and Andersen 1996). Basidiospores produced on a hymenium are 7-10 x 4-7 $\mu \mathrm{m}$, hyaline, smooth, and prominently apiculate (Parmeter 1970). The basidiospores are sometimes produced on the leaf and sheath tissue, but the 
importance of basidiospores on disease spread in turfgrass is unknown (Smiley et al. 2005). Rhizoctonia can grow saprophytically in the soil, spread through mycelial growth from neighboring plants, or rely on germinating bulbils on infected plant materials for dispersal of the pathogen (Aoyagi et al. 1998; Parmeter 1970; Smiley et al. 2005).

Rhizoctonia solani is classified into fourteen anastomosis groups (AG) which are categorized by hyphal interactions between two isolates of $R$. solani (Carling et al. 2002). If a field isolate and a tester isolate have hyphal fusion occur, they belong to the same AG (Anderson 1982). AG 1, AG 2-2, and AG 4 are the most common anastomosis groups isolated from turfgrasses (Smiley et al. 2005). Rhizoctonia solani that causes large patch on warm-season grasses belongs to AG 2-2, as does $R$. solani that causes brown patch on cool-season grasses. However, within AG 2-2, there are three intraspecific groups (ISGs): IIIB, which causes brown patch on cool-season turfgrasses, IV, which mainly infects sugar beet, and LP, which causes large patch on warm-season turfgrasses. These ISGs differ genetically and in morphology, optimal growth temperature, and pathogenicity (Aoyagi et al. 1998; Hyakumachi et al. 1998). AG 2-2 LP has dark brown, aerial mycelium with irregular zonation, which lacks bulbil formation on potato dextrose agar (PDA). Compared to AG 2-2 IIIB and IV, AG 2-2 LP has the slowest growth rate and grows within a range of 10 to $30^{\circ} \mathrm{C}$ with an optimum growth temperature of $23^{\circ} \mathrm{C}$ (Aoyagi et al. 1998; Hyakumachi et al. 1998). AG 2-2 IV has buff- to brown-colored non-aerial mycelium, and grows optimally at $28^{\circ} \mathrm{C}$. AG $2-2 \mathrm{IIIB}$ mycelium is buff to brown in color, non-aerial, and also grows optimally at $28^{\circ} \mathrm{C}$, but can also grow up to $35^{\circ} \mathrm{C}$ unlike either AG 2-2 LP or IV isolates (Hyakumachi et al. 1998). Mycelium of all 
three ISGs is white in color early in growth and turns brown during incubation (Hyakumachi et al. 1998).

\section{Penetration and Infection by Rhizoctonia}

Rhizoctonia solani most often infects through direct penetration of plant tissue, but entry through wounds, lenticels, and stomata have also been observed (Dodman et al. 1968; Nakayama 1940; Ramsey 1917). Direct penetration of Rhizoctonia into a plant mainly occurs through a mechanical process (Baker and Bateman 1978; Brookhouser et al. 1980; Dodman et al. 1968; Matsumoto 1921). Before infection, Rhizoctonia hyphae grow over and adhere tightly to the plant surface, often along the anticlinal walls of the epidermis (Armentrout and Downer 1987). A mucilage-like substrate has sometimes been observed around the hyphae during infection, which helps the fungus adhere to the plant surface (Armentrout and Downer 1987; Matsuura 1986). The growth and T-shaped branching of $R$. solani causes hyphal accumulation along the plant surface, leading to the formation of appressoria, or dome-shaped infection cushions, at infection sites (Dodman et al. 1968; Parmeter 1970). To mechanically penetrate the plant surface, fine infection pegs exert hydrostatic pressure and penetrate into the plant cell with the aid of the hyphal mass behind them (Armentrout and Downer 1987; Matsuura 1986). After R. solani penetrates the cuticle, the mycelia grow inter- and intracellularly (Kenning and Hanchey 1980).

Infection may also occur through enzymatic processes. Rhizoctonia spp. are necrotrophic pathogens and can produce secondary metabolites to facilitate infection and degradation of infected plant tissue (Brooks 2007; Couch 1995; Kenning and Hanchey

1980; Mandava et al. 1980; Smiley et al. 2005). The phytotoxins phenylacetic acid and 
fumaric acid are both produced by R. solani (Hyakumachi et al. 1980; Mandava et al. 1980). The enzyme cutinase may play a role in initial penetration of $R$. solani into plant tissue (Dodman et al. 1968). Endopolygalacturonase and cutinase are produced by $R$. solani at the infection peg tip in response to cotton hypocotyl exudates to macerate tissue during the infection process (Baker and Bateman 1978; Brookhouser et al. 1980; Brookhouser and Weinhold 1979). Endopectinlyase, another pectolytic enzyme, is also involved in later stages of tissue infection. Rhizoctonia solani strains lacking endopectinlyase were hypovirulent (Marcus et al. 1986).

\section{Fungal Melanin and Its Role in Infection}

Fungal melanins are located in the cell walls or as extracellular polymers around fungal cells (Bell and Wheeler 1986). Melanin protects spores from UV light and solar radiation, and higher melanin concentration in cell walls is proportional to degree of protection from damage (Bell and Wheeler 1986; Eisenman and Casadevall 2012; Langfelder et al. 2003). When compared to hyaline spores or hyphae, melanized fungi have more resistance to lysis and damage. Melanin-deficient mutant fungi have less resistance to lysis and damage. Melanin-deficient mutant fungi are also more prone to digestion from hydrolytic enzymes as well (Bell and Wheeler 1986).

There are two melanin biosynthesis pathways found in fungi: the DHN and DOPA pathways (Eisenman and Casadevall 2012; Langfelder et al. 2003). Fungi that synthesize melanin through the DOPA pathway form melanin through an enzymatic process similar to mammalian melanin biosynthesis, and start with tyrosine or L-3,4dihydroxyphenylalanine (L-dopa) as a melanin precursor (Bell and Wheeler 1986; Eisenman and Casadevall 2012; Pawelek and Körner 1982). Melanins formed through 
the DOPA pathway are brown-black eumelanins or the reddish-brown pheomelanin, which incorporates sulfur in its synthesis (Eisenman and Casadevall 2012; Land et al. 2004). In the DHN pathway, the precursor acetyl- or malonyl-coA is catalyzed by polyketide synthase (PKS), and the process forms intermediates such as scytalone and finally DHN (1,8-dihydroxynaphthalene), which polymerizes to form melanin (Bell et al. 1976; Bell and Wheeler 1986; Eisenman and Casadevall 2012; Langfelder et al. 2003). DHN-melanins contain only carbon, hydrogen, and oxygen, while DOPA-melanins also contain nitrogen (Eisenman and Casadevall 2012).

Fungal melanin plays a key role in pathogenesis and virulence (Bell and Wheeler 1986; Eisenman and Casadevall 2012; Langfelder et al. 2003). In the plant pathogenic fungi Magnaporthe grisea and Colletotrichum spp., a layer of melanin reinforces the fungal cell wall and is used to build up turgor pressure in the appressorium to penetrate the plant host (Bell and Wheeler 1986). Colletotrichum lagenarium albino mutants and mutants lacking a PKS gene were less able to penetrate cellulose membranes with their appressoria (Kubo et al. 1982). Similarly, transforming Pks1- mutants with a melanin biosynthesis gene from Alternaria alternate (AMS) melanized the outer layer of the appressoria and allowed them to penetrate a cellulose membrane as effectively as the wild-type $C$. lagenarium, but they were less able to penetrate cucumber leaves and produced smaller lesions (Takano et al. 1997). Magnaporthe and Colletotrichum mutants unable to synthesize melanin via the scytalone or pentaketide pathways as well as isolates treated with fungicides targeting melanin biosynthesis cannot form melanin and cannot infect the host plant (Howard and Valent 1996; Mendgen and Deising 1993). Colletotrichum kahawae conidia treated with tricyclazole formed unmelanized 
appressoria that only produced a quarter of the turgor pressure as the untreated control, and were much less effective at infecting coffee leaves and berries than the control (Chen et al. 2004).

Melanin from $R$. solani AG1-IA, the causal agent of rice sheath blight, has been recently characterized (Chen et al. 2015). Melanin extracted from mature bulbils of $R$. solani cultures (Rs-melanin) was physically and chemically similar to synthetic DOPA melanin. Both types of melanin were insoluble in water and organic solvents and bleached in $\mathrm{NaOCl}$ and $\mathrm{H}_{2} \mathrm{O}_{2}$, though the synthetic melanin bleached quicker than the Rsmelanin. UV-vis spectra of both melanin types were similar, while the IR spectra had some differences. Rs-melanin showed peaks at 2922 and $2852 \mathrm{~cm}^{-1}$, which did not occur in the synthetic DOPA melanin. Melanin extracted from U. maydis had similar peaks on the IR spectrum as Rs-melanin (Chen et al. 2015).

Sneh et al. (1989) noted that a hypovirulent strain of $R$. solani was also melanin deficient. When compared to a virulent isolate of $R$. solani AG 4, which had melanized hyphae and produced brown bulbils, the hypovirulent isolate produced hyaline hyphae without bulbils. Hyphae were also thinner in diameter when compared to the virulent strain. After inoculation of both isolates onto cotton seedlings, the virulent strain was observed to penetrate and grow inside the seedlings, while the hypovirulent strain did not penetrate and colonized on the outer surface of the seedlings (Sneh et al. 1989). In another study on melanin producing $(\mathrm{M}+)$ and melanin non-producing (M-) R. solani AG 1-IA, the dark brown $\mathrm{M}+$ phenotype produced large brown necrotic lesions on rice sheaths, while the whiter M- phenotype produced very small lesions. It was also found that temperature played an important role in melanin biosynthesis. The highest melanin 
production occurred at $25^{\circ} \mathrm{C}$, less production occurred at $30^{\circ} \mathrm{C}$, and no melanin was produced at $20^{\circ} \mathrm{C}$ (Kim et al. 2001). These studies indicate the importance of melanin production in the ability of $R$. solani infection of plant hosts.

\section{Nitrogen and Rhizoctonia Disease Severity}

The effect of nitrogen on plant diseases has been studied extensively (Cahill et al. 1983; Fidanza and Dernoeden 1996a; Huber and McCay-Buis 1993; Huber and Thompson 2007; Smiley and Cook 1973; Smiley et al. 1996). Generally, nitrogen has been associated with higher plant disease incidence, but this does not take timing, form, previous soil conditions, and interactions with other elements into account (Huber and Thompson 2007). Similarly, many studies on $R$. solani have been dedicated to nitrogen impact on disease severity. High pre-flood $\mathrm{N}$ rates increased initial disease severity of rice sheath blight ( $R$. solani AG 1-IA), but by the middle or late reproductive growth stages, the lesion height was uniform across nitrogen application rates and fertilization methods (Slaton et al. 2003). Fewer potato plants were infected with Rhizoctonia stem canker when fertilized with calcium nitrate compared to those fertilized with ammonium sulfate, indicating nitrogen source also effects Rhizoctonia disease incidence (Huber and Sumner 1996).

Rhizoctonia is able to translocate nutrients such as phosphate and carbon from its external environment to hyphae large distances from the nutrient source (Thrower and Thrower 1968). Nutrient deficiency of the pathogen has been demonstrated to play a role in the infection process of $R$. solani. Weinhold et al. (Weinhold et al. 1969) examined the ability of $R$. solani to infect while deficient in nutrients. When lacking in carbon or nitrogen, Rhizoctonia grew vegetatively on the surface of cotton seedlings, but no 
infection structures formed and pathogenicity was greatly reduced. However, a subsequent study by Weinhold et al. (1972) found mycelium could rapidly assimilate nutrients in the environment to compensate for a deficiency and regain pathogenicity. Initially, the fungus was grown on minimal media containing $0.5 \mathrm{~g} \mathrm{~L}^{-1}$ asparagine. The $R$. solani inoculum from the media had low virulence on sand-grown cotton seedlings, but produced larger lesions on cotton seedlings grown in soil. Adding supplemental nitrogen sources to sand media also increased lesion size compared to sand without additional nitrogen (Weinhold et al. 1972).

Smiley et al. (1996) compared inorganic nitrogen sources to organic nitrogen sources in a study on Rhizoctonia root rot of wheat ( $R$. solani AG 8). Applications of ammonium nitrate were broadcast yearly from 1987 to 1988 and urea ammonium nitrate was banded $15 \mathrm{~cm}$ deep in 1989 , both at rates of either 45 or $90 \mathrm{~kg} \mathrm{~N} \mathrm{ha}^{-1}$. These were compared to applications of $111 \mathrm{~kg} \mathrm{~N} \mathrm{ha}^{-1}$ of cow manure and $34 \mathrm{~kg} \mathrm{ha}^{-1}$ of pea vine. The inorganic ammonium nitrate and urea ammonium nitrate led to higher Rhizoctonia root rot disease incidence in wheat compared to treatments of the organic fertilizers and no added nitrogen (Smiley et al. 1996).

\section{Impact of Nitrogen on Turfgrass Diseases}

In turfgrasses, nitrogen is the essential mineral nutrient required in the largest amount and is most often supplemented with fertilizer applications. Because of its mobility in plants, nitrogen will often be removed by the regular mowing that occurs in a turfgrass system (Christians 2007). Nitrogen is necessary for chlorophyll, amino acids, proteins, enzymes, and vitamins, all of which are critical for healthy plant functions (Christians 2007; Datnoff et al. 2007; McCarty 2003). Ammonium $\left(\mathrm{NH}_{4}^{+}\right)$and nitrate 
$\left(\mathrm{NO}_{3}{ }^{-}\right)$are the only two forms of nitrogen used by turfgrass and though many forms of nitrogen are applied to turfgrasses, they all must be converted to these two forms to be available for plant uptake (McCarty 2003). Symptoms of nitrogen deficiency include chlorosis along with slowed growth and low shoot density (Christians 2007). However, excessive or untimely nitrogen applications discourage root growth in favor of shoot growth and can make the plants susceptible to heat, cold, drought, disease, nematode, and wear damage. Nitrogen that is not taken up by the plant can be lost due to leaching, denitrification, and volatilization, making it the most limiting mineral nutrient in turfgrass growth. Excessive or untimely nitrogen applications should be avoided to prevent nitrate leaching into waterways (McCarty 2003).

Because of the vital role of nitrogen in maintaining high-quality turfgrass, extensive research has been done on the impacts of nitrogen fertility practices on multiple turfgrass diseases, including application rates and carrier form. Nitrogen application has been shown to impact multiple foliar turfgrass diseases in different ways. Red thread disease, a foliar and sheath disease caused by the fungus Laetisaria fuciformis, was reduced on both fescue (Festuca rubra L. var. Ranier) and on an Astoria bentgrass (Agrostis tenuis Sibth. var. Astoria) and red fescue mix when nitrogen rates were increased, while lower nitrogen rates promoted the disease (Cahill et al. 1983). High nitrogen rates of readily available nitrogen such as ammonium nitrate decreased dollar spot caused by Sclerotinia homoeocarpa on creeping bentgrass (Agrostis palustris Huds.) (Markland et al. 1969). Conversely, high nitrogen may also cause an increase in severity of certain foliar turfgrass diseases. Excessive nitrogen is linked to higher Pythium blight severity (Pythium spp.) (Smiley et al. 2005). On cool-season grasses, excessive nitrogen 
applications have been correlated with an increase in brown patch (Rhizoctonia solani AG 2-2 IIIB). Increasing nitrogen rates and nitrogen applications during the summer disease period leads to higher brown patch severity on tall fescue (Festuca arundinacea Schreb.) and seaside bentgrass (Agrostis stolonifera var. palustris) (Bloom and Couch 1960; Burpee 1995; Cutulle et al. 2014; Fidanza and Dernoeden 1996b; Vincelli and Powell 1996; Vincelli et al. 1997; Watkins and Wit 1993). Brown patch severity was also lower when sulfur-coated urea (SCU) was applied compared to sodium nitrate $\left(\mathrm{NaNO}_{3}\right)$. Although low $\mathrm{pH}$ was weakly correlated with lower disease levels, the reduction in disease may have actually been impacted by the slow release characteristics of the SCU fertilizer rather than its soil acidification properties (Fidanza and Dernoeden 1996b).

Nitrogen source also impacts the severity of several soilborne turfgrass diseases. Dernoeden et al. (1991) reported an increase in survivability of 'Tufcote' bermudagrass in growth chambers after inoculation with spring dead spot (SDS) causing Leptosphaeria korrae when fertilized with ammonium sulfate $\left[\left(\mathrm{NH}_{4}\right)_{2} \mathrm{SO}_{4}\right]$ compared to unfertilized plants or those fertilized with other nitrogen sources. In a field study, ammonium sulfatetreated plots showed the greatest SDS recovery. Ammonium-based fertilizers also led to higher green up on bermudagrass. Low soil $\mathrm{pH}$ was correlated with higher green up and less SDS damage (Dernoeden 1991). Nitrogen source also impacts summer patch (Magnaporthe poae) on Kentucky bluegrass (Poa pratensis L.). Summer patch symptoms were less severe when treated with an $\mathrm{NH}_{4}{ }^{+}-\mathrm{N}$ source compared to $\mathrm{NO}_{3}{ }^{-} \mathrm{N}$. High rates of nitrate were also linked to the greatest level of disease, while higher $\mathrm{NH}_{4}{ }^{+}-$ $\mathrm{N}$ rates led to the lowest amount of disease (Thompson et al. 1995). 


\section{Chemical Management of Large Patch}

Use of fungicides to control large patch may be necessary on highly maintained areas such as golf course fairways. Typically, two fungicide applications split between the fall and spring infection periods can help control the disease, but additional applications may be necessary on areas with high disease pressure. Preventative applications can be planned for early fall or early spring before noticeable symptoms on areas where large patch has been severe in the past. Curative applications can provide some control, but may not show benefits until zoysiagrass is more actively growing (Vincelli et al. 2017). Repeated use of fungicide raises concerns for development of fungicide resistance in certain turfgrass pathogens such as Sclerotinia homoeocarpa (dollar spot), Pythium spp. (Pythium root rot, Pythium root dysfunction, and Pythium blight), and Colletotrichum graminicola (anthracnose), but there are currently no reports of fungicide resistance observed in $R$. solani AG 2-2 LP (Avila-Adame et al. 2003; Golembiewski et al. 1995; Moorman and Kim 2004).

Several fungicides are labeled for large patch control on warm-season grasses, including azoxystrobin (quinone outside inhibitor; FRAC Code 11), flutolanil (succinate dehydrogenase inhibitor; FRAC Code 7), and tebuconazole (demethylation inhibitor;

FRAC Code 3). These three fungicides are xylem-mobile or acropetal systemic fungicides, meaning they move upwards in the plant from where they are applied. Nozzles that allow more leaf coverage with smaller droplets or air induction nozzles which help with drift reduction can improve control of dollar spot on creeping bentgrass (Kaminski and Fidanza 2009; Kennelly and Wolf 2009). Spray volumes as low as 203.7 $\mathrm{L} \mathrm{H}_{2} \mathrm{O}$ ha $^{-1}$ were comparable to $814.9 \mathrm{~L} \mathrm{H}_{2} \mathrm{O}$ ha $^{-1}$ for controlling dollar spot as well, 
which means less water usage and spray tank fill-ups for golf course superintendents (Kennelly and Wolf 2009). Although large patch is a foliar disease, infection occurs lower in the zoysiagrass canopy than dollar spot infection on creeping bentgrass cut to putting green height. Spray deposition to the lower canopy increases with increasing water carrier volume. In one study, fungicide droplets placed on the sheath and stems of zoysiagrass had greater control of large patch than those placed only on the leaf.

Increasing spray rates also led to greater droplet deposition lower in the canopy and greater disease control (Benelli 2016).

\section{Host Resistance}

Managing large patch can be environmentally and economically costly due to the input of fungicides, so choosing varieties that have resistance is important to reduce these costs. There are currently no Zoysia spp. completely resistant to large patch (Vargas 2005). The cultivars 'Meyer', 'Cavalier', and 'Zorro' have moderate resistance to large patch disease. 'Diamond' and 'Marquis' are moderately susceptible, and 'Belair', 'Crowne', 'El Toro', 'Emerald', 'Omni', 'Palisades', 'and 'Sunburst' are highly susceptible to the disease (Metz et al. 1994; Patton 2009). In the 2007-2012 National Turfgrass Evaluation program, the commercially available 'Zorro' (vegetative) and 'Shadowturf' (vegetative) varieties of Zoysia matrella incurred less large patch severity than the Zoysia japonica varieties 'Meyer' (vegetative) and 'Zenith' (seeded) (National Turfgrass Evaluation Program 2012). At Kansas State University, trials were conducted to evaluate large patch resistance on 14 freeze-tolerant zoysiagrass progeny and 'Meyer' zoysiagrass, since freezing tolerance is necessary for zoysiagrass survival in the upper transition zone winters. In growth chamber studies, all 14 progeny had similar disease 
levels to 'Meyer', while only six progeny had consistent disease severity as low as 'Meyer' in the field. No correlation was observed between growth chamber and field studies, emphasizing the importance of environmental conditions on large patch (Obasa et al. 2012).

\section{Cultural Management Practices}

There is a paucity of information regarding the impact of cultural practices on large patch development. Rhizoctonia solani is favored by damp, humid environments to incite disease. Therefore, reducing leaf surface wetness and proper drainage can limit disease severity (Smiley et al. 2005). Like many other turfgrass diseases, mowing also has an influence on disease incidence. Mowing heights of 4.5 and $5.1 \mathrm{~cm}$ led to lower shoot density reduction and less sheath blighting from large patch compared to lower heights of 2.5 and $1.3 \mathrm{~cm}$. Therefore, raising the mowing heights during the infection period is recommended (Green et al. 1994). Cultivation practices such as verti-cutting and core-aerification have been anecdotally linked to development of new infection points through movement of infected material to previously healthy sites (Spurlock 2009). Summer cultivation has no effect on patch size and disease development and is recommended to sustain plant health (Obasa et al. 2013).

On cool-season grasses, nitrogen has been correlated with an increase in brown patch disease caused by Rhizoctonia solani AG 2-2 IIIB (Bloom and Couch 1960; Burpee 1995; Fidanza and Dernoeden 1996a). Green et al. (1994) researched the effect of nitrogen application rates on large patch incidence on zoysiagrass. Urea, urea formaldehyde, poultry litter, sewage sludge, and bovine waste were used as nitrogen sources at rates of 74 or $148 \mathrm{~kg} \mathrm{~N} \mathrm{ha}^{-1}$ per year applied in June and August. Neither 
nitrogen application rate nor synthetic versus natural nitrogen sources had any impact on large patch severity (Green et al. 1994).

Obasa et al. (2013) examined the effect of nitrogen timing on large patch incidence. In the study, spring and fall applications of urea led to a decrease in large patch symptoms in two of three sites when compared to plots receiving nitrogen only in the summer. This was unexpected because of the link between nitrogen applications during brown patch activity and increased brown patch severity in the summer (Bloom and Couch 1960; Burpee 1995; Cutulle et al. 2014; Fidanza and Dernoeden 1996b; Vincelli and Powell 1996; Vincelli et al. 1997; Watkins and Wit 1993). In 2016, a follow up study by Miller et al. (2016) found that spring nitrogen applications did not increase large patch severity when compared to the standard summer nitrogen applications. The finding that nitrogen application timing impacts large patch disease severity, along with nitrogen application rates having no effect on disease severity, is contrary to the common idea that nitrogen applied during conditions favorable to Rhizoctonia solani growth would enhance disease severity (Couch 2000; Fidanza and Dernoeden 1996b; Green et al. 1994; Obasa et al. 2013; Smiley et al. 2005). These practices should be investigated more in depth to determine if an effective large patch management strategy could be developed involving nitrogen fertility.

\section{Research Objectives}

Little research has been done to investigate the effects of cultural practices on large patch incidence. Nitrogen applications on zoysiagrass have been avoided in the fall and spring during the disease period due to concern of increased large patch severity (Smiley et al. 2005). However, there is no research linking nitrogen applications to 
increased large patch (Green et al. 1994). A spring and fall nitrogen application was observed to decrease large patch incidence in two of three tested sites (Obasa et al. 2013). Additionally, a preliminary laboratory trial at the University of Missouri found that $R$. solani AG 2-2 LP grown on nitrogen-amended media containing $\left(\mathrm{NH}_{4}\right)_{2} \mathrm{SO}_{4}$ as a primary nitrogen source remained white, while cultures grown on $\mathrm{PDA}$ or $\mathrm{Ca}\left(\mathrm{NO}_{3}\right)_{2}$-amended media had brown-pigmented mycelium typically associated with wild-type $R$. solani AG 2-2 LP. Lack of melanin production reduces pathogenicity and infection capabilities of certain fungal plant pathogens, including some $R$. solani AGs (Kim et al. 2001; Kubo et al. 1982; Mendgen and Deising 1993; Sneh et al. 1989). Nitrogen applications during the large patch disease period using nitrogen sources that reduce pathogen growth and infection could potentially be an alternative to multiple chemical inputs in controlling large patch outbreaks.

Research was initiated with the following specific objectives:

1. To evaluate the effects of three commonly used nitrogen sources with and without a $\mathrm{pH}$ buffer on the radial growth, morphology, and infection potential of $R$. solani AG 2-2 LP.

In vitro and in vivo studies examined the impact of nitrogen source on the growth and morphology of $R$. solani AG 2-2 LP as well as the infection capability of the pathogen after exposure to a specific nitrogen source while in culture. Urea, calcium nitrate, and ammonium sulfate are three common nitrogen sources used in turfgrass fertility programs. Hacskaylo et al. (1954) demonstrated that the utilization of ammonium-based nitrogen sources lowers the $\mathrm{pH}$ of the fungal growth medium environment and decreased fungal growth compared to cultures grown on nitrate-based 
media. Adding the $\mathrm{pH}$ buffer fumaric acid increased the growth of some fungal species on ammonium sulfate media, suggesting the $\mathrm{pH}$ of the media influences fungal growth (Hacskaylo et al. 1954). The use of a pH buffer in vitro would also more closely resemble soil $\mathrm{pH}$ buffering conditions, allowing for a more field-applicable evaluation of nitrogen source utilization of $R$. solani AG 2-2 LP. In the greenhouse, $R$. solani AG 2-2 LP exposed to different nitrogen sources was used as inoculum on Zoysia japonica plants. Through this study, a relationship between culture morphology and infection rate may be determined. If $R$. solani functions similarly to $M$. grisea, then colonies lacking melanin should have a delayed infection initiation compared to those initially containing melanin. If so, nitrogen source choice may be critical to inhibit disease incidence.

2. Investigate the impact of nitrogen source, application timing, and a single spring fungicide application on large patch incidence on zoysiagrass.

Currently, large patch remains a major issue on highly maintained zoysiagrass fairways and tees. Fungicide treatments are both an economically and environmentally costly concern on the large area of zoysiagrass fairways in the United States Transition Zone. Nitrogen applications made during brown patch outbreaks on cool season turf exacerbated disease symptoms (Bloom and Couch 1960; Burpee 1995; Fidanza and Dernoeden 1996b). Due to similar taxonomy of the pathogens causing brown patch ( $R$. solani AG 2-2 IIIB) and large patch (R. solani AG 2-2 LP), management strategies for brown patch on cool-season turfgrasses have been adapted to warm-season turfgrasses to avoid large patch outbreaks. However, disease symptoms are present at different growth periods for their respective hosts. Brown patch symptoms are present on cool-season grasses while they are experiencing decline in the hot summer temperatures, while large 
patch symptoms are noticeable on warm-season grasses when the grass is either going into or exiting winter dormancy in the cool fall and spring weather (Hyakumachi et al. 1998). Obasa et al. (2013) found that large patch symptoms lessened in two of three sites when nitrogen was applied in both spring and fall, while Miller et al. (2016) found that spring applications did not increase large patch severity compared to the summer standard nitrogen fertility schedule. Therefore, Nitrogen source and application timing in the fall and spring were evaluated for their effects on large patch incidence on 'Meyer' zoysiagrass. Also, a single spring fungicide application was evaluated for disease control. Typically, fall and spring applications are used to treat large patch, but a single application would be much more economical and have less ecological impact (Patton and Latin 2004). A greenhouse fertility study evaluated the impact of nitrogen source on large patch infection of zoysiagrass. The goal of these studies was to integrate current fertility practices with a single fungicide application to control large patch on zoysiagrass. 


\section{Literature Cited}

Anderson, N. A. 1982. The genetics and pathology of Rhizoctonia solani. Annual Review of Phytopathology 20:329-347.

Aoyagi, T., Kageyama, K., and Hyakumachi, M. 1998. Characterization and survival of Rhizoctonia solani AG2-2 LP associated with large patch disease of zoysia grass. Plant Disease 82:857-863.

Armentrout, V., and Downer, A. 1987. Infection cushion development by Rhizoctonia solani on cotton. Phytopathology 77:619-623.

Avila-Adame, C., Olaya, G., and Köller, W. 2003. Characterization of Colletotrichum graminicola isolates resistant to strobilurin-related QoI fungicides. Plant Disease 87:1426-1432.

Baker, C. J., and Bateman, D. 1978. Cutin degradation by plant pathogenic fungi. Phytopathology 68:1577-1584.

Bell, A. A., and Wheeler, M. H. 1986. Biosynthesis and functions of fungal melanins. Annual Review of Phytopathology 24:411-451.

Bell, A. A., Puhalla, J. E., Tolmsoff, W. J., and Stipanovic, R. D. 1976. Use of mutants to establish (+)-scytalone as an intermediate in melanin biosynthesis by Verticillium dahliae. Canadian Journal of Microbiology 22:787-799.

Benelli, J. J. 2016. Improved Fungicidal Control of Large Patch through Optimal Use of Surfactants and Spray Rate Volume. PhD diss., University of Tennessee.

Bloom, J. R., and Couch, H. B. 1960. Influence of environment on disease of turfgrasses. I. Effect of nutrition, $\mathrm{pH}$, and soil moisture on Rhizoctonia brown patch. Phytopathology 50.

Brookhouser, L., and Weinhold, A. 1979. Induction of polygalacturonase from Rhizoctonia solani by cotton seed and hypocotyl exudates. Phytopathology 69:599-602.

Brookhouser, L., Hancock, J., and Weinhold, A. 1980. Characterization of endopolygalacturonase produced by Rhizoctonia solani in culture and during infection of cotton seedlings. Phytopathology 70:1039-1042.

Brooks, S. A. 2007. Sensitivity to a phytotoxin from Rhizoctonia solani correlates with sheath blight susceptibility in rice. Phytopathology 97:1207-1212.

Burpee, L., and Martin, B. 1992. Biology of Rhizoctonia species associated with turfgrasses. Plant Disease 76:112-117. 
Burpee, L. L. 1995. Interactions among mowing height, nitrogen fertility, and cultivar affect the severity of Rhizoctonia blight of tall fescue. Plant Disease 79:721-726.

Burpee, L. L., and Martin, S. B. 1996. Biology of turfgrass diseases incited by Rhizoctonia species. Pages 359-368 in: Rhizoctonia Species: Taxonomy, Molecular Biology, Ecology, Pathology and Disease Control. Springer.

Cahill, J. V., Murray, J. J., O'Neill, N. R., and Dernoedon, P. H. 1983. Interrelationships between fertility and Corticum red thread fungal disease of turfgrass. Plant Disease 67:1080-1083.

Carling, D., Kuninaga, S., and Brainard, K. 2002. Hyphal anastomosis reactions, rDNAinternal transcribed spacer sequences, and virulence levels among subsets of Rhizoctonia solani anastomosis group-2 (AG-2) and AG-BI. Phytopathology 92:43-50.

Chen, J., Wang, C., Shu, C., Zhu, M., and Zhou, E. 2015. Isolation and characterization of a melanin from Rhizoctonia solani, the causal agent of rice sheath blight. Eur J Plant Pathol 142:281-290.

Chen, Z., Nunes, M. A., Silva, M. C., and Jr, C. J. R. 2004. Appressorium turgor pressure of Colletotrichum kahawae might have a role in coffee cuticle penetration. Mycologia 96:1199-1208.

Christians, N. 2007. Fundamentals of Turfgrass Management. 3rd ed. John Wiley \& Sons, Inc, Hoboken, NJ.

Christias, C., and Lockwood, J. 1973. Conservation of mycelial constituents in four sclerotium-forming fungi in nutrient-deprived conditions. Phytopathology 63.

Couch, H. B. 1995. Diseases of Turfgrasses. Third ed. Krieger Publishing Company, Malabar, FL.

Couch, H. B. 2000. The Turfgrass Disease Handbook. Krieger Publishing Company, Malabar, FL.

Cutulle, M., Derr, J., McCall, D., Nichols, A., and Horvath, B. 2014. Effect of mowing height and fertility on bermudagrass (Cynodon dactylon) encroachment and brown patch severity in tall fescue. Weed Technology 28:225-232.

Datnoff, L. E., Elmer, W. H., and Huber, D. M. 2007. Mineral Nutrition and Plant Disease. American Phytopathological Society (APS Press).

Dernoeden, P. H. 1991. Reducing spring dead spot severity. Pages 68-80 in: Golf Course Management GCSAA. 
Dernoeden, P. H., Crahay, J. N., and Davis, D. B. 1991. Spring dead spot and bermudagrass quality as influenced by nitrogen source and potassium. Crop Science 31:1674-1680.

Dodman, R., Barker, K., and Walker, J. 1968. A detailed study of the different modes of penetration by Rhizoctonia solani. Phytopathology 58:1271-1276.

Dunn, J., and Diesburg, K. 2004. Turf Management in The Transition Zone. 1st ed. John Wiley \& Sons, Inc., Hoboken, NJ.

Eisenman, H., and Casadevall, A. 2012. Synthesis and assembly of fungal melanin. Appl Microbiol Biotechnol 93:931-940.

Fidanza, M. A., and Dernoeden, P. H. 1996a. Interaction of nitrogen source, application timing, and fungicide on Rhizoctonia blight in ryegrass. HortScience 31:389-392.

Fidanza, M. A., and Dernoeden, P. H. 1996b. Brown patch severity in perennial ryegrass as influenced by irrigation, fungicide, and fertilizers. Crop Sci. 36:1631-1638.

Fry, J., Kennelly, M., and St. John, R. 2008. Zoysiagrass: economic and environmental sense in the transition zone. Golf Course Management 76:127-132.

Golembiewski, R., Vargas, J., Jones, A., and Detweiler, A. 1995. Detection of demethylation inhibitior (DMI) resistance in Sclerotinia homoeocarpa populations. Plant Disease 79:491-493.

Green, D., Fry, J., Pair, J., and Tisserat, N. 1994. Influence of management practices on Rhizoctonia large patch disease in zoysiagrass. HortScience 29:186-188.

Green II, D. E., Fry, J. D., Pair, J. C., and Tisserat, N. A. 1993. Pathogenicity of Rhizoctonia solani AG-2-2 and Ophiosphaerella herpotricha on zoysiagrass. Plant Disease 77:1040-1044.

Hacskaylo, J., Lilly, V. G., and Barnett, H. 1954. Growth of fungi on three sources of nitrogen. Mycologia 46:691-701.

Howard, R. J., and Valent, B. 1996. Breaking and entering: host penetration by the fungal rice blast pathogen Magnaporthe grisea. Annual Review of Microbiology 50:491512.

Huber, D. M., and McCay-Buis, T. S. 1993. A multiple component analysis of the takeall disease of cereals. Plant Dis. 77:437-447.

Huber, D. M., and Sumner, D. R. 1996. Suppressive soil amendments for the control of Rhizoctonia species. Pages 433-443 in: Rhizoctonia Species: Taxonomy, Molecular Biology, Ecology, Pathology and Disease Control. Springer. 
Huber, D. M., and Thompson, I. A. 2007. Nitrogen and plant disease. in: Mineral Nutrition and Plant Disease. APS, St. Paul.

Hyakumachi, M., Kobayashi, K., and Ui, T. 1980. Production of Fumaric Acid by Rhizoctonia solani. Japanese Journal of Phytopathology 46:121-125.

Hyakumachi, M., Mushika, T., Ogiso, Y., Toda, T., Kageyama, K., and Tsuge, T. 1998. Characterization of a new cultural type (LP) of Rhizoctonia solani AG2 2 isolated from warm season turfgrasses, and its genetic differentiation from other cultural types. Plant Pathology 47:1-9.

Kaminski, J. E., and Fidanza, M. A. 2009. Dollar spot severity as influenced by fungicide mode of activity and spray nozzle. HortScience 44:1762-1766.

Kennelly, M. M., and Wolf, R. E. 2009. Effect of nozzle type and water volume on dollar spot control in greens-height creeping bentgrass. Applied Turfgrass Science 6:0-0.

Kenning, L. A., and Hanchey, P. 1980. Ultrastructure of lesion formation in Rhizoctoniainfected bean hypocotyls. Phytopathology 70:998-1004.

Kim, H. T., Chung, Y. R., and Cho, K. Y. 2001. Mycelial melanization of Rhizoctonia solani AG1 affecting pathogenicity in rice. The Plant Pathology Journal 17:210215.

Kubo, Y., Suzuki, K., Furusawa, I., Ishida, N., and Yamamoto, M. 1982. Relation of appressorium pigmentation and penetration of nitrocellulose membranes by Colletotrichum lagenarium. Phytopathology 72:498-501.

Land, E. J., Ramsden, C. A., and Riley, P. A. 2004. Quinone chemistry and melanogenesis. Pages 88-109 in: Methods in Enzymology, vol. Volume 378. S. Helmut and P. Lester, eds. Academic Press.

Langfelder, K., Streibel, M., Jahn, B., Haase, G., and Brakhage, A. A. 2003. Biosynthesis of fungal melanins and their importance for human pathogenic fungi. Fungal Genetics and Biology 38:143-158.

Mandava, N. B., Orellana, R. G., Warthen Jr, J. D., Worley, J. F., Dutky, S. R., Finegold, H., and Weathington, B. C. 1980. Phytotoxins in Rhizoctonia solani: Isolation and biological activity of $m$-hydroxy-and $m$-methoxyphenylacetic acids. Journal of Agricultural and Food Chemistry 28:71-75.

Marcus, L., Barash, I., Sneh, B., Koltin, Y., and Finkler, A. 1986. Purification and characterization of pectolytic enzymes produced by virulent and hypovirulent isolates of Rhizoctonia solani Kühn. Physiological and Molecular Plant Pathology 29:325-336.

Markland, F. E., Roberts, E. C., and Frederick, L. R. 1969. Influence of nitrogen fertilizers on Washington creeping bentgrass, Agrostis palustris Huds. II. 
Incidence of dollar spot, Sclerotinia homoeocarpa, infection. Agronomy Journal 61:701-705.

Matsumoto, T. 1921. Studies in the physiology of the fungi. XII. Physiological specialization in Rhizoctonia solani Kühn. Annals of the Missouri Botanical Garden 8:1-62.

Matsuura, K. 1986. Scanning electron microscopy of the infection process of Rhizoctonia solani in leaf sheaths of rice plants. Phytopathology 76:811-814.

McCarty, L. B. 2003. Fundamentals of turfgrass and agricultural chemistry. John Wiley $\&$ Sons.

Mendgen, K., and Deising, H. 1993. Infection structures of fungal plant pathogens - a cytological and physiological evaluation. New Phytologist 124:193-213.

Metz, S., Colbaugh, P., and Engelke, M. 1994. Rhizoctonia blight susceptibility among commercial and experimental zoysiagrasses. TX Turfgrass Res.-1993, Consolidated Prog. Rep. PR-5129:82-83.

Miller, G. L., Earlywine, D. T., Braun, R., Fry, J. D., and Kennelly, M. M. 2016. Influence of Nitrogen Source and Application Timing on Large Patch of Zoysiagrass. Crop, Forage \& Turfgrass Management 2.

Missouri Valley Turfgrass Association. 1999. Missouri Turfgrass Economic Impact Survey.

Moorman, G., and Kim, S. 2004. Species of Pythium from greenhouses in Pennsylvania exhibit resistance to propamocarb and mefenoxam. Plant Disease 88:630-632.

Nakayama, T. 1940. A study on the infection of cotton seedlings by Rhizoctonia solani. Annals of the Phytopathological Society of Japan 10:93-103.

National Turfgrass Evaluation Program. 2012. National Zoysiagrass Test: 2007-2012 data. Beltsville, MD.

Obasa, K., Fry, J., and Kennelly, M. 2012. Susceptibility of zoysiagrass germplasm to large patch caused by Rhizoctonia solani. HortScience 47:1252-1256.

Obasa, K., Fry, J., Bremer, D., John, R. S., and Kennelly, M. 2013. Effect of cultivation and timing of nitrogen fertilization on large patch disease of zoysiagrass. Plant Disease 97:1075-1081.

Parmeter, J. R. 1970. Rhizoctonia solani, Biology and Pathology. Univ of California Press.

Patton, A. 2010. Selecting zoysiagrass cultivars: Turf quality and stress tolerance. Golf Course Management 78:90-95. 
Patton, A., and Reicher, Z. 2007. Zoysiagrass winter hardiness. Golf Course Management:119-123.

Patton, A. J. 2009. Selecting Zoysiagrass Cultivars: Turfgrass Quality, Growth, Pest and Environmental Stress Tolerance. Applied Turfgrass Science 6.

Patton, A. J., and Latin, R. 2004. Fungicide selection and timing for Rhizoctonia large patch control. Annual Report. Purdue University Turfgrass Science Program.

Pawelek, J. M., and Körner, A. M. 1982. The biosynthesis of mammalian melanin: The regulation of pigment formation, the key to disorders such as albinism and piebaldism, may also offer some clues for the treatment of melanoma. American Scientist 70:136-145.

Ramsey, G. B. 1917. A form of potato disease produced by Rhizoctonia. Journal of Agricultural Research 9:421-426.

Slaton, N. A., Cartwright, R. D., Meng, J., Gbur, E. E., and Norman, R. J. 2003. Sheath blight severity and rice yield as affected by nitrogen fertilizer rate, application method, and fungicide. Agronomy Journal 95:1489-1496.

Smiley, R., and Cook, R. 1973. Relationship between take-all of wheat and rhizosphere $\mathrm{pH}$ in soils fertilized with ammonium vs. nitrate-nitrogen. Phytopathology 63:882-890.

Smiley, R. W., Collins, H. P., and Rasmussen, P. E. 1996. Diseases of wheat in long-term agronomic experiments at Pendleton, Oregon. Plant Disease 80:813-820.

Smiley, R. W., Dernoeden, P. H., and Clarke, B. B. 2005. Compendium of Turfgrass Diseases. 3rd ed. APS Press, St. Paul, MN.

Sneh, B., Ichielevich-Auster, M., and Shomer, I. 1989. Comparative anatomy of colonization of cotton hypocotyls and roots by virulent and hypovirulent isolates of Rhizoctonia solani. Canadian Journal of Botany 67:2142-2149.

Sneh, B., Burpee, L., and Ogoshi, A. 1991. Identification of Rhizoctonia Species. APS Press.

Spurlock, T. N. 2009. Epidemiology and Etiology of Zoysiagrass Diseases in Northwest Arkansas. ProQuest.

SRI International. 2011. The Missouri Golf Economy.

Stalpers, J. A., and Andersen, T. F. 1996. A synopsis of the taxonomy of teleomorphs connected with Rhizoctonia s.1. Pages 49-63 in: Rhizoctonia Species: Taxonomy, Molecular Biology, Ecology, Pathology and Disease Control. Springer. 
Sumner, D. R. 1996. Sclerotia formation by Rhizoctonia species and their survival. Pages 207-215 in: Rhizoctonia Species: Taxonomy, Molecular Biology, Ecology, Pathology and Disease Control. Springer.

Takano, Y., Kubo, Y., Kawamura, C., Tsuge, T., and Furusawa, I. 1997. The Alternaria alternata melanin biosynthesis gene restores appressorial melanization and penetration of cellulose membranes in the melanin-deficient albino mutant of Colletotrichum lagenarium. Fungal Genetics and Biology 21:131-140.

Thompson, D. C., Clarke, B. B., and Heckman, J. R. 1995. Nitrogen form and rate of nitrogen and chloride application for the control of summer patch in Kentucky bluegrass. Plant Disease 79:51-56.

Thrower, L., and Thrower, S. 1968. Movement of nutrients in fungi. II. The effect of reproductive structures. Australian Journal of Botany 16:81-87.

Townsend, B. B., and Willetts, H. J. 1954. The development of sclerotia of certain fungi. Transactions of the British Mycological Society 37:213-221.

Vargas, J. M. J. 2005. Management of Turfgrass Diseases. 3rd ed. John Wiley and Sons, Inc., Hoboken, NJ.

Vincelli, P., and Powell, A. 1996. Impact of mowing height and nitrogen fertility on brown patch of tall fescue. Biological and Cultural Control Tests for the Control of Plant Diseases 11:34.

Vincelli, P., Williams, D., and Powell, A. 1997. Increasing brown patch on tall fescue with increasing mowing height and spring/summer nitrogen fertility. Phytopathology 86:S100-S101.

Vincelli, P., Clarke, B., and Munshaw, G. 2017. Chemical control of turfgrass diseases 2017.

Watkins, J., and Wit, L. 1993. Effect of nitrogen level and cutting height on brown patch severity, 1992. Biological and Cultural Control Tests for the Control of Plant Diseases 8:124.

Weinhold, A., Bowman, T., and Dodman, R. 1969. Virulence of Rhizoctonia solani as affected by nutrition of the pathogen. Phytopathology.

Weinhold, A., Dodman, R., and Bowman, T. 1972. Influence of exogenous nutrition on virulence of Rhizoctonia solani. Phytopathology 62:278-281. 


\section{CHAPTER 2}

Impact of nitrogen source and a pH buffer on the in vitro growth and morphology of Rhizoctonia solani AG 2-2 LP

As published in International Turfgrass Society Research Journal Vol. 13, 2017, p. 1-5 
Impact of nitrogen source and a $\mathrm{pH}$ buffer on the in vitro growth and morphology of Rhizoctonia solani AG 2-2 LP

\section{Abstract}

Large patch (LP) disease of zoysiagrass (Zoysia japonica Steud.) caused by the fungal pathogen Rhizoctonia solani AG 2-2 LP is an important disease in the United States transition zone that limits the utility and aesthetics of lawns and golf fairways. A preliminary study has shown that $R$. solani grown on ammonium-based media remained white, while isolates grown on nitrate-based media and potato dextrose agar (PDA) were melanized and brown. This study aimed to evaluate the effects of nitrogen source and a $\mathrm{pH}$ buffer on the radial growth and morphology of $R$. solani AG 2-2 LP. Forty isolates were initially grown on antibiotic amended PDA and transferred to water agar (WA). Mycelial plugs from WA were transferred to basal media amended with ammonium sulfate (AMS), calcium nitrate $(\mathrm{CN})$, or urea at concentrations of $0,50,100,200,400$, and $800 \mu \mathrm{g} \mathrm{ml}^{-1}$. A second set of each concentration was also amended with fumaric acid (FA) $\mathrm{pH}$ buffer. All media was brought to $\mathrm{pH}=7.0$ prior to autoclaving. Radial growth was recorded after four days. Isolates grown on $\mathrm{CN}$ had the greatest radial growth, isolates grown on AMS were intermediate, and urea-grown isolates had the least radial growth $(P<0.0001)$. Radial $R$. solani colony growth increased with increasing $\mathrm{CN}$ concentration, but growth decreased with increasing AMS and urea concentrations. Fumaric acid increased radial growth on all N-sources. All isolates melanized on media amended with $\mathrm{CN}$ and urea. Isolates grown on $200 \mu \mathrm{g} \mathrm{ml}^{-1} \mathrm{AMS}$ melanized with FA, but remained white without FA. If melanin plays a role in pathogen infection and pathogen 
survival, a fertility program involving AMS may be useful in an integrated strategy to suppress large patch.

\section{Introduction}

'Meyer' zoysiagrass (Zoysia japonica Steud.) is a popular variety of warm-season turfgrass for lawns, golf fairways, and tees throughout Missouri and the upper transition zone of the United States due to its excellent cold, heat and drought tolerance (Christians, 2007, Dunn and Diesburg, 2004, Fry, et al., 2008). Though zoysiagrass is relatively disease resistant, large patch disease caused by the pathogen Rhizoctonia solani Kühn AG 2-2 LP continues to limit the utility and aesthetics of zoysiagrass fairways and lawns (Hyakumachi, et al., 1998, Smiley, et al., 2005). Large patch symptoms appear as circular matted areas of brown or sometimes orange turf. When active, the pathogen causes reddish-brown lesions on the leaf sheaths that can spread into the stem. Affected plants may also rot at the base of the sheath, and are easily pulled from their stolons in advanced stages of the disease (Couch, 2000). Bright orange margins, known as "firing" symptoms, surrounding the patches may also be observed in both spring and fall. The patches range from 1 to over 8 meters in diameter and expand rapidly in wet, cool weather. Severe infection results in rings or patches of almost completely killed turf, and recovery may be slow due to the limited growth of zoysia during the infection period in spring and fall (Dunn and Diesburg, 2004, Smiley, et al., 2005).

Nitrogen applications on turfgrass have been shown to impact turfgrass disease in different ways. Incidence of red thread (Laetisaria fuciformis) and dollar spot (Sclerotinia homeocarpa) decreases with higher nitrogen rates, while excessive nitrogen increases severity of Pythium blight (Pythium spp.) and brown patch (Rhizoctonia solani) 
(Cahill, et al., 1983, Fidanza and Dernoeden, 1996, Markland, et al., 1969). Nitrogen source has also been demonstrated to impact the severity of several soilborne turfgrass diseases (Dernoeden, et al., 1991, Thompson, et al., 1995). When plants take up ammonium-based nitrogen, the soil $\mathrm{pH}$ decreases, while nitrate-based nitrogen causes an increase in soil pH (Barber and Riley, 1971, Miller, et al., 1970, Smiley and Cook, 1973). Ammonium-based nitrogen $\left(\mathrm{NH}_{4} \mathrm{SO}_{4}, \mathrm{NH}_{4} \mathrm{Cl}\right)$ decreases soil $\mathrm{pH}$ and spring dead spot (SDS) severity on bermudagrass (Cynodon dactylon (L.) Pers.) compared to untreated and nitrate-based nitrogen $\left(\mathrm{NaNO}_{3}\right)$ (Dernoeden, et al., 1991). The growth of the pathogens that cause SDS (Ophiosphaerella herpotrica (Fr.) J. Walker and O. korrae (J. Walker \& A. M. Sm. bis.) Shoemaker and C. E. Babc.) also decreased on ammonium sulfate $\left[\left(\mathrm{NH}_{4}\right)_{2} \mathrm{SO}_{4}\right]$ media compared to calcium nitrate $\left[\mathrm{Ca}\left(\mathrm{NO}_{3}\right)_{2}\right]$ media, and decreasing pH was also associated with decreased pathogen growth (Cottrill, et al., 2015). Nitrogen source also impacts summer patch on Kentucky bluegrass caused by Magnaporthe poae Landsch. and Jacks., with high rates of $\mathrm{NO}_{3}-\mathrm{N}$ linked to the greater disease severity, and higher $\mathrm{NH}_{4}-\mathrm{N}$ rates reducing the amount of disease (Thompson, et al., 1995).

The influence of nitrogen source on the growth of $R$. solani AG 2-2 LP is unknown. A preliminary laboratory trial found that $R$. solani AG 2-2 LP grown on nitrogen amended media containing ammonium sulfate $\left[\left(\mathrm{NH}_{4}\right)_{2} \mathrm{SO}_{4}\right]$ as a nitrogen source remained white, while mycelium on PDA and calcium nitrate $\left[\mathrm{Ca}\left(\mathrm{NO}_{3}\right)_{2}\right]$ media had brown-pigmented mycelium typically associated with the wild-type. Loss of melanin production in other plant pathogenic fungi, such as Magnaporthe grisea (Hebert) Barr and Colletotrichum lagenarium (Pass.) Ellis and Halstead, led to a loss of pathogenicity 
(Kubo, et al., 1982, Mendgen and Deising, 1993). However it has not been reported in $R$. solani AG 2-2 LP. Utilization of a specific nitrogen source in the field could not only limit the growth of the LP pathogen, but also potentially limit penetration into the host. Therefore, this research is aimed to evaluate the effects of nitrogen source and a $\mathrm{pH}$ buffer on the radial growth and morphology of $R$. solani AG 2-2 LP.

\section{Materials and Methods}

Mycelial growth response on three different nitrogen sources at a range of concentrations and one buffer was determined for 40 isolates of Rhizoctonia solani AG 22 LP. Isolates were obtained from infected zoysiagrass and bermudagrass samples collected from Kansas, Missouri, and Illinois in 2011 - 2015. Leaf sheaths from symptomatic grass were cut into small segments $(3-5 \mathrm{~mm})$, and rinsed under water for 30 minutes to remove spores and soil from the surface. After rinsing, the segments were then surface sterilized with a 70\% ethanol solution in water for 30 seconds. Sections were rinsed twice with sterile water, blotted dry on a sterile paper towel, and plated on water agar $\left(15 \mathrm{~g} \mathrm{~L}^{-1}\right)$ medium (WA). After three days of growth, hyphae matching $R$. solani AG 2-2 LP morphology (right-angle branching, pinched at branching, septate) were transferred to potato dextrose agar $\left(39 \mathrm{~g} \mathrm{~L}^{-1}\right)$ amended with chloramphenicol (50 mg $\left.\mathrm{L}^{-1}\right)$, tetracycline $\left(50 \mathrm{mg} \mathrm{L}^{-1}\right)$, and streptomycin sulfate $\left(50 \mathrm{mg} \mathrm{L}^{-1}\right)$ (PDA+++). Isolates were stored at $-80^{\circ} \mathrm{C}$ on sterilized filter paper.

Growth medium for nitrogen source assessment was adapted from He and Suzuki (2003). The basal medium contained $20 \mathrm{~g}$ dextrose, $15 \mathrm{~g}$ agar, $0.30 \mathrm{~g} \mathrm{~K}_{2} \mathrm{HPO}_{4}, 0.30 \mathrm{~g}$ $\mathrm{MgSO}_{4}, 0.10 \mathrm{~g} \mathrm{CaCl}_{2}, 0.30 \mathrm{mg} \mathrm{ZnSO}$, $0.15 \mathrm{mg} \mathrm{FeSO}$, $0.10 \mathrm{mg} \mathrm{CuSO}$, $0.50 \mathrm{mg}$ thiamine hydrochloride, $0.10 \mathrm{mg}$ nicotinamide, and $0.02 \mathrm{mg}\left(\mathrm{NH}_{4}\right)_{6} \mathrm{Mo}_{7} \mathrm{H}_{2} \mathrm{O}$ per $1 \mathrm{~L}$ of 
distilled water (He and Suzuki 2003). The medium was amended with 0, 50, 100, 200, 400 , or $800 \mu \mathrm{g} \mathrm{ml} l^{-1}$ of either calcium nitrate $\left[\mathrm{Ca}\left(\mathrm{NO}_{3}\right)_{2} \bullet 4\left(\mathrm{H}_{2} \mathrm{O}\right)\right]$, ammonium sulfate $\left[\left(\mathrm{NH}_{4}\right)_{2} \mathrm{SO}_{4}\right]$, or urea to act as the sole nitrogen source (Cottrill, et al., 2015). Each set of media was duplicated, and $200 \mu \mathrm{g} \mathrm{ml}^{-1}$ fumaric acid (granular), a $\mathrm{pH}$ buffer for fungal growth media (Hacskaylo, et al., 1954), was added to mimic soil pH buffering capacity. Each media set was brought to $\mathrm{pH} 7.0$ before autoclaving using $\mathrm{NaOH}$ and lactic acid $\left(\mathrm{C}_{3} \mathrm{H}_{6} \mathrm{O}_{3}\right)$. The $\mathrm{pH}$ of the media was measured again after autoclaving (Table 2.1). After autoclaving, media was allowed to cool to $50^{\circ} \mathrm{C}$ and poured into $100 \mathrm{~mm} \times 15 \mathrm{~mm}$ sterile petri dishes (ThermoFisher Scientific, Waltham, MA) to cool and solidify.

Prior to plating on nitrogen media, isolates were taken out of long-term storage and grown on PDA+++, and then transferred to PDA+++ again for one week of growth. Isolates were then transferred to WA. After seven days, $9 \mathrm{~mm}$ circular plugs with active mycelial growth were removed from WA and transferred to the center each nitrogen media. Plates were sealed with parafilm and put in a $25^{\circ} \mathrm{C}$ incubator for four days. After four days, mycelial diameters were measured in two perpendicular directions. Each of the forty isolates was repeated three times on each media type, and the experiment was conducted two times. The $\mathrm{pH}$ of isolates was also measured after 7-days growth to see if any changes occurred. Media of select isolates was melted down, mycelium was removed, and the $\mathrm{pH}$ of a $50 \mathrm{ml}$ aliquot of melted media was measured (Table 2.1).

To determine color of the isolates, pictures of ten isolates were taken after 14-20 days of growth to account for difference in time of melanin manifestation between the isolates. A white felt cloth was used as a background. Colors of the plate area were averaged using the Filter->Blur->Average setting in Photoshop (Adobe Photoshop ${ }^{\circledR}$ 
CS4). The Red-Green-Blue hue values were recorded from each media type on each isolate, and these values were averaged to create a single gray scale hue from 0 to 255 . Values closer to 0 were considered "dark brown" and values closer to 255 were white or colorless. Petri dishes with the nitrogen media were used as a blank color control. Isolates were also transferred to PDA to determine if isolates regained pigmentation ability when transferred to a complete growth medium.

Least square means (LSMeans) of mycelial diameters and culture gray scale hues were subjected to analysis of variance using PROC GLIMMIX procedure in SAS (version 9.3; SAS Institute. Cary, NC). Means were separated using Fisher's protected LSD $(\alpha=0.05)$. Regression was assessed for colony growth trends using PROC REG procedure.

\section{Results}

\section{Radial Growth of $\boldsymbol{R}$. solani Isolates}

Radial colony growth of Rhizoctonia solani AG 2-2 LP on calcium nitrate was significantly higher compared to growth on either ammonium sulfate or urea $(P<$ 0.0001), while colony growth on ammonium sulfate was significantly greater than on urea $(P<0.0001)$. Increasing concentrations of calcium nitrate were associated with increasing colony diameter, while ammonium sulfate and urea concentration were inversely related to radial growth (Figures 2.1, 2.2). All concentrations of calcium nitrate produced significantly more growth than the $0 \mathrm{~N}$ media $(P<0.0001)$. Ammonium sulfate growth was significantly greater than $0 \mu \mathrm{g} \mathrm{ml}^{-1}$ media at 50, 100, 200, (P < $0.0001)$ and $400 \mu \mathrm{g} \mathrm{ml}^{-1}(\mathrm{P}=0.0002)$, but not at $800 \mu \mathrm{g} \mathrm{ml}^{-1}$ ammonium sulfate $(P=$ 0.0774). On urea media, only growth at $50 \mu \mathrm{g} \mathrm{ml}^{-1}$ urea was statistically greater than 0 
$\mu \mathrm{g} \mathrm{m} l^{-1}(P=0.0057)$, and 400 and $800 \mu \mathrm{g} \mathrm{ml}^{-1}$ urea produced statistically less growth than the control $(P<0.0001)$.

Fumaric acid buffer significantly increased the overall growth of $R$. solani compared to those grown on non-buffered media $(P=0.0018)$. Growth trends for $R$. solani on each nitrogen source were not affected by fumaric acid $(\mathrm{P}>0.05)$ (Figure 2.2). The buffer did not significantly increase overall $R$. solani isolate growth on either calcium nitrate or urea media compared to non-buffered media of the same nitrogen source $(P>0.05)$, but growth was significantly increased on buffered ammonium sulfate media compared to the non-buffered ammonium sulfate media $(P=0.0115)$. The $\mathrm{pH}$ of ammonium sulfate media after $R$. solani isolate growth was affected by the addition of fumaric acid buffer. Fumaric acid stabilized the media $\mathrm{pH}$ of ammonium sulfate media concentrations of 0 to $200 \mu \mathrm{g} \mathrm{ml}^{-1}$ compared to non-buffered ammonium sulfate media at the same concentrations. A dramatic $\mathrm{pH}$ drop was noted at higher concentrations of ammonium sulfate in both non-buffered and buffered ammonium sulfate media (Table 2.1). Notable $\mathrm{pH}$ differences were not noticed in either urea or calcium nitrate after growth of $R$. solani.

\section{Morphology of Isolates}

Media type, concentration, and fumaric acid buffer all significantly impacted the hue of the isolates $(\mathrm{P}<0.0001)$. Urea-grown colonies were darkest in hue, calcium nitrate colonies were intermediate in hue, and ammonium sulfate produced the lightest colonies. Colonies grown on fumaric acid buffered media were generally darker than the non-buffered counterparts. All isolates grown on $0 \mu \mathrm{g} \mathrm{N} \mathrm{ml}^{-1}$ media were hyaline. Isolates decreased in hue, or increased in dark brown pigmentation, as nitrogen 
concentration increased in both urea and calcium nitrate media (Tables 2.2, 2.3).

Ammonium sulfate-grown isolates began to form melanin at 50 and $100 \mu \mathrm{g} \mathrm{ml}^{-1}$ for both non-buffered and buffered media and also when grown on $200 \mu \mathrm{g} \mathrm{m} \mathrm{m}^{-1}$ ammonium sulfate plus $200 \mu \mathrm{g} \mathrm{ml}^{-1}$ fumaric acid amended media (Figure 2.3). Rhizoctonia solani remained white in color when grown on $200 \mu \mathrm{g} \mathrm{ml}^{-1}$ non-buffered ammonium sulfate and on 400 or $800 \mu \mathrm{g} \mathrm{ml}^{-1}$ ammonium sulfate with and without the buffer. When transferred to PDA, all media types turned brown within 7-10 days after transfer, including those grown on $0 \mu \mathrm{g}$ $\mathrm{ml}^{-1}$ media and high ammonium sulfate concentrations that were initially white.

\section{Discussion}

In this study, Rhizoctonia solani AG 2-2 LP showed a mycelial growth preference on calcium nitrate-based media compared to ammonium sulfate- or urea-based media. The extreme negative relationship between urea concentration and $R$. solani isolate growth was unexpected. Some of the limited $R$. solani growth on urea may be attributed to toxicity at high nitrogen concentrations, since urea is $46.62 \% \mathrm{~N}$ compared to $11.86 \%$ and $21.07 \% \mathrm{~N}$ for calcium nitrate and ammonium sulfate, respectively. In the field, spring and fall ammonium sulfate applications have been shown to increase zoysiagrass green cover during spring large patch active periods compared to calcium nitrate treatments and urea applications, though the results were inconsistent between trial locations and dates (Miller, et al., 2016). The results of this laboratory trial support the field findings that ammonium sulfate has a negative impact on large patch pathogen growth when compared to calcium nitrate, and expands on the finding by showing increasing concentrations of ammonium sulfate negatively impact growth. 
High ammonium sulfate concentrations also inhibited production of melanin in $R$. solani AG 2-2 LP, while colonies grown on calcium nitrate and urea increased in dark pigmentation as nitrogen concentration increased. Melanin is important for UV protection in some fungal species and is also present in $R$. solani survival structures known as bulbils (Bell and Wheeler, 1986, Smiley, et al., 2005). Sneh et al. (Sneh, et al., 1989) noted that a hypovirulent strain of $R$. solani was also melanin deficient. When compared to a virulent isolate of $R$. solani AG 4, which had melanized hyphae and produced brownish sclerotia (bulbils), the hypovirulent isolate produced hyaline hyphae without sclerotia. After inoculation of both isolates onto cotton seedlings, the virulent strain was observed to penetrate and grow inside the seedlings, while the hypovirulent strain did not penetrate and colonized on the outer surface of the seedlings (Sneh, et al., 1989). In another study on melanin producing (M+) and melanin non-producing (M-) $R$. solani AG 1-IA, the dark brown $\mathrm{M}+$ phenotype produced large brown necrotic lesions on rice sheaths, while the whiter M- phenotype produced very small lesions (Kim, et al., 2001). If melanin in $R$. solani AG 2-2 LP functions similarly to AG 4 or 1-1A melanin, inhibiting melanin production could disrupt penetration into the host, or even prevent the production of the pigmented bulbils necessary for overwintering.

The lack of melanin production in this study could be due to decreased $\mathrm{pH}$ from $R$. solani utilizing ammonium sulfate as a nitrogen source. If so, this result may not be replicated as effectively in the field, as soil or thatch layer $\mathrm{pH}$ buffering could allow the pathogen to still produce melanin similarly to buffered $200 \mu \mathrm{g} \mathrm{ml}^{-1}$ ammonium sulfate media. When transferred to PDA ( $\mathrm{pH}=5.5)$, all isolates, including those that were originally white on ammonium sulfate, turned brown. Green et al. (Green, et al., 1994) 
researched the effect of nitrogen application rates on large patch incidence on zoysiagrass. Urea, urea formaldehyde, poultry litter, sewage sludge, and bovine waste were used as nitrogen sources at rates of 74 or $148 \mathrm{~kg} \mathrm{~N} \mathrm{ha}^{-1}$ per year applied in June and August. Nitrogen source or application rate did not have an effect on large patch severity when applied only twice (Green, et al., 1994). Although increasing urea-based nitrogen in the field did not have an impact on large patch disease, increasing ammonium sulfate applications may produce a different effect. Future studies should focus on increasing ammonium sulfate application rates and persistent applications of ammonium sulfate during the growing year to determine if large patch severity can be reduced. A field study on spring, summer, and fall applications of calcium nitrate, urea, and ammonium sulfate is currently being conducted to investigate nitrogen source persistence and its effect on large patch disease on zoysiagrass. 


\section{Literature Cited}

Barber, S. and D. Riley. 1971. Effect of ammonium and nitrate fertilization on phosphorus uptake as related to root-induced $\mathrm{pH}$ changes at the root-soil interface. Soil Science Society of America Journal 35: 301-306.

Bell, A.A. and M.H. Wheeler. 1986. Biosynthesis and functions of fungal melanins. Annual Review of Phytopathology 24: 411-451.

Cahill, J.V., J.J. Murray, N.R. O'Neill and P.H. Dernoedon. 1983. Interrelationships between fertility and Corticum red thread fungal disease of turfgrass. Plant Disease 67: 1080-1083.

Christians, N. 2007. Fundamentals of Turfgrass Management. 3rd ed. John Wiley \& Sons, Inc, Hoboken, NJ.

Cottrill, D.J., D.T. Earlywine and G.L. Miller. 2015. Assessment of Nitrogen Source, Sulfur, and Fall Fungicide Applications on the Management of Spring Dead Spot of Bermudagrass. Plant Disease 100: 473-482.

Couch, H.B. 2000. The Turfgrass Disease Handbook. Krieger Publishing Company, Malabar, FL.

Dernoeden, P.H., J.N. Crahay and D.B. Davis. 1991. Spring dead spot and bermudagrass quality as influenced by nitrogen source and potassium. Crop Science 31: 16741680.

Dunn, J.H. and K. Diesburg. 2004. Turf Management in the Transition Zone. 1st ed. John Wiley \& Sons, Inc., Hoboken, NJ.

Fidanza, M.A. and P.H. Dernoeden. 1996. Interaction of nitrogen source, application timing, and fungicide on Rhizoctonia blight in ryegrass. HortScience 31: 389-392.

Fry, J., M. Kennelly and R. St. John. 2008. Zoysiagrass: economic and environmental sense in the transition zone. Golf Course Management 76: 127-132.

Green, D., J. Fry, J. Pair and N. Tisserat. 1994. Influence of management practices on Rhizoctonia large patch disease in zoysiagrass. HortScience 29: 186-188.

Hacskaylo, J., V.G. Lilly and H. Barnett. 1954. Growth of fungi on three sources of nitrogen. Mycologia 46: 691-701.

He, X.M. and A. Suzuki. 2003. Effect of nitrogen resources and $\mathrm{pH}$ on growth and fruit body formation of Coprinopsis phlyctidospora. Fungal Diversity 12: 35-44. 
Hyakumachi, M., T. Mushika, Y. Ogiso, T. Toda, K. Kageyama and T. Tsuge. 1998. Characterization of a new cultural type (LP) of Rhizoctonia solani AG2 2 isolated from warm season turfgrasses, and its genetic differentiation from other cultural types. Plant Pathology 47: 1-9.

Kim, H.T., Y.R. Chung and K.Y. Cho. 2001. Mycelial melanization of Rhizoctonia solani AG1 affecting pathogenicity in rice. The Plant Pathology Journal 17: 210-215.

Kubo, Y., K. Suzuki, I. Furusawa, N. Ishida and M. Yamamoto. 1982. Relation of appressorium pigmentation and penetration of nitrocellulose membranes by Colletotrichum lagenarium. Phytopathology 72: 498-501.

Markland, F.E., E.C. Roberts and L.R. Frederick. 1969. Influence of nitrogen fertilizers on Washington creeping bentgrass, Agrostis palustris Huds. II. Incidence of dollar spot, Sclerotinia homoeocarpa, infection. Agronomy Journal 61: 701-705.

Mendgen, K. and H. Deising. 1993. Infection structures of fungal plant pathogens - a cytological and physiological evaluation. New Phytologist 124: 193-213.

Miller, G.L., D.T. Earlywine, R. Braun, J.D. Fry and M.M. Kennelly. 2016. Influence of Nitrogen Source and Application Timing on Large Patch of Zoysiagrass. Crop, Forage \& Turfgrass Management 2.

Miller, M.H., C.P. Mamaril and G.J. Blair. 1970. Ammonium effects on phosphorus absorption through $\mathrm{pH}$ changes and phosphorus precipitation at the soil-root interface. Agronomy Journal 62: 524-527.

Smiley, R. and R. Cook. 1973. Relationship between take-all of wheat and rhizosphere $\mathrm{pH}$ in soils fertilized with ammonium vs. nitrate-nitrogen. Phytopathology 63: $882-890$.

Smiley, R.W., P.H. Dernoeden and B.B. Clarke. 2005. Compendium of Turfgrass Diseases. 3rd ed. APS Press, St. Paul, MN.

Sneh, B., M. Ichielevich-Auster and I. Shomer. 1989. Comparative anatomy of colonization of cotton hypocotyls and roots by virulent and hypovirulent isolates of Rhizoctonia solani. Canadian Journal of Botany 67: 2142-2149.

Thompson, D.C., B.B. Clarke and J.R. Heckman. 1995. Nitrogen form and rate of nitrogen and chloride application for the control of summer patch in Kentucky bluegrass. Plant Disease 79: 51-56. 


\begin{tabular}{|c|c|c|c|c|}
\hline \multirow{2}{*}{$\begin{array}{l}\text { Ammonium Sulfate } \\
\text { Concentration }\end{array}$} & \multicolumn{2}{|c|}{ Non-buffered Media } & \multicolumn{2}{|c|}{ Fumaric Acid(+) Media } \\
\hline & $\begin{array}{c}\text { After } \\
\text { autoclave }\end{array}$ & $\begin{array}{l}\text { After 7-d } \\
\text { growth }\end{array}$ & $\begin{array}{c}\text { After } \\
\text { Autoclave }\end{array}$ & $\begin{array}{l}\text { After 7-d } \\
\text { growth }\end{array}$ \\
\hline$\mu \mathrm{g} \mathrm{ml^{-1 }}$ & & & & \\
\hline 0 & 6.0 & 6.7 & 6.0 & 6.3 \\
\hline 50 & 6.0 & 6.0 & 6.0 & 6.1 \\
\hline 100 & 6.2 & 4.8 & 6.2 & 5.8 \\
\hline 200 & 6.2 & 3.3 & 6.0 & 5.5 \\
\hline 400 & 6.2 & 2.2 & 6.0 & 3.1 \\
\hline 800 & 6.0 & 1.4 & 6.0 & 1.6 \\
\hline
\end{tabular}

Table 2.1 Nitrogen media pHs after autoclaving and after 7-days growth of isolates. The source of nitrogen for all media was ammonium sulfate. 


\section{Concentration $\left(\mu \mathrm{g} \mathrm{mL}^{-1}\right)$}

\begin{tabular}{cccccccc}
\hline & & 0 & 50 & 100 & 200 & 400 & 800 \\
\cline { 3 - 8 } CN & No Buffer & $162 \mathrm{ab}$ & $157 \mathrm{bcde}$ & $151 \mathrm{e}$ & $139 \mathrm{f}$ & $114 \mathrm{gh}$ & $108 \mathrm{~h}$ \\
& FA(+) & $165 \mathrm{a}$ & $157 \mathrm{bcde}$ & $151 \mathrm{de}$ & $138 \mathrm{f}$ & $113 \mathrm{gh}$ & $98 \mathrm{i}$ \\
\multirow{2}{*}{ AMS } & No Buffer & $165 \mathrm{a}$ & $155 \mathrm{cde}$ & $151 \mathrm{de}$ & $161 \mathrm{abc}$ & $163 \mathrm{ab}$ & $163 \mathrm{ab}$ \\
& FA(+) & $166 \mathrm{a}$ & $155 \mathrm{cde}$ & $140 \mathrm{f}$ & $120 \mathrm{~g}$ & $160 \mathrm{abc}$ & $161 \mathrm{abc}$ \\
\multirow{2}{*}{ Urea } & No Buffer & $158 \mathrm{bcd}$ & $134 \mathrm{f}$ & $117 \mathrm{~g}$ & $97 \mathrm{ij}$ & $86 \mathrm{k}$ & $91 \mathrm{jk}$ \\
& FA(+) & $160 \mathrm{abc}$ & $135 \mathrm{f}$ & $108 \mathrm{~h}$ & $91 \mathrm{jk}$ & 711 & $62 \mathrm{~m}$ \\
\hline
\end{tabular}

Table 2.2 Gray scale values of Rhizoctonia solani AG 2-2 LP isolates. Values are an average hue from ten isolates. Values closer to 0 are considered "dark brown" and values closer to 255 are white or colorless. Potato dextrose agar has a pigmentation value of 54, and a blank media plate has a value of 167. 


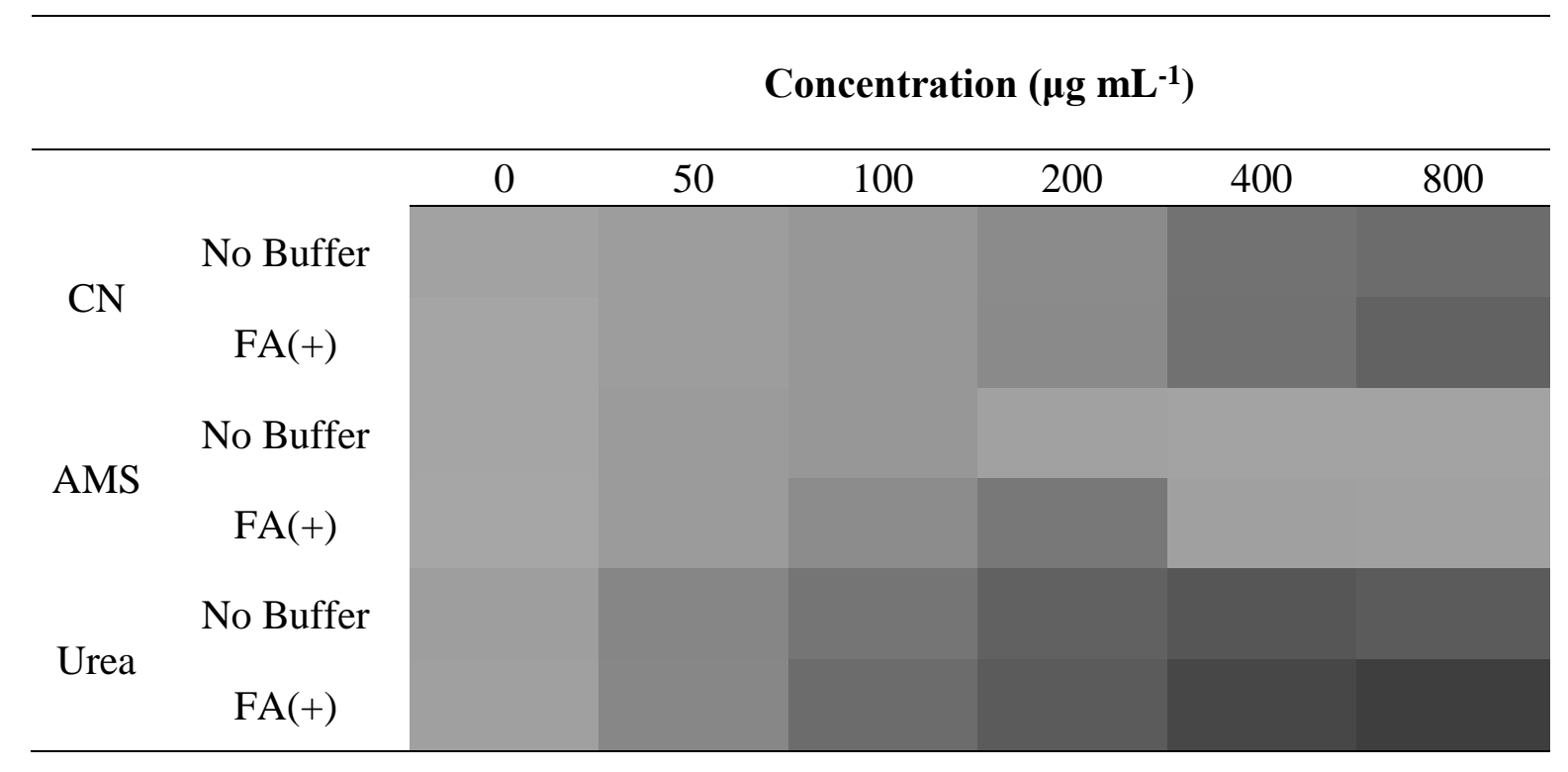

Table 2.3 Gray scale pigmentation of Rhizoctonia solani AG 2-2 LP isolates. Gray color represents the average of the R-G-B values of the actual hue of the mycelial colonies. Lighter gray on the chart indicates closer to colorless or white, while darker gray is closer to dark brown pigmentation. 


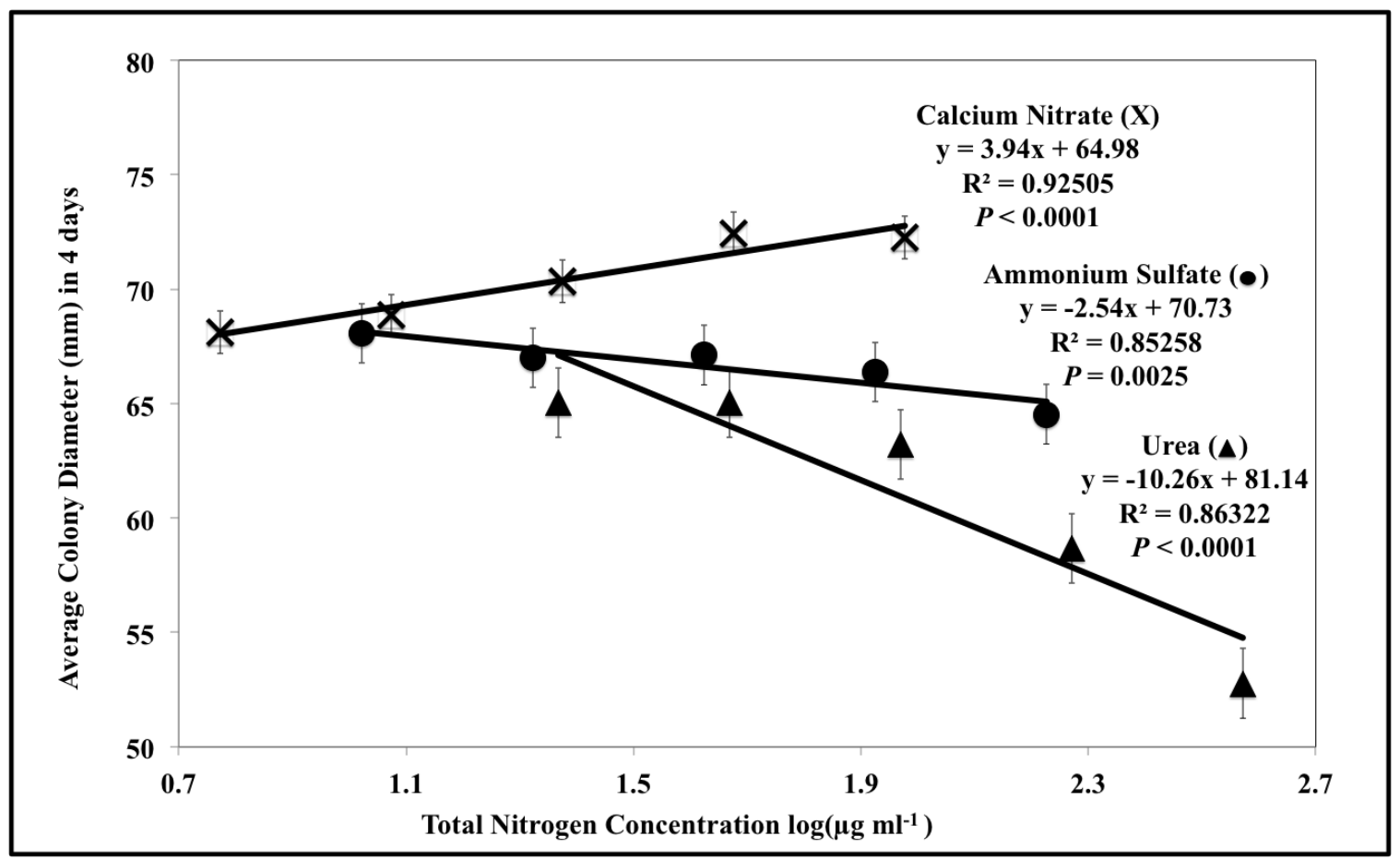

Figure 2.1 Radial large patch isolate growth on a non-buffered basal medium amended with calcium nitrate, ammonium sulfate, or urea. Means are averaged across all isolates. Error bars represent the standard error of the mean. 


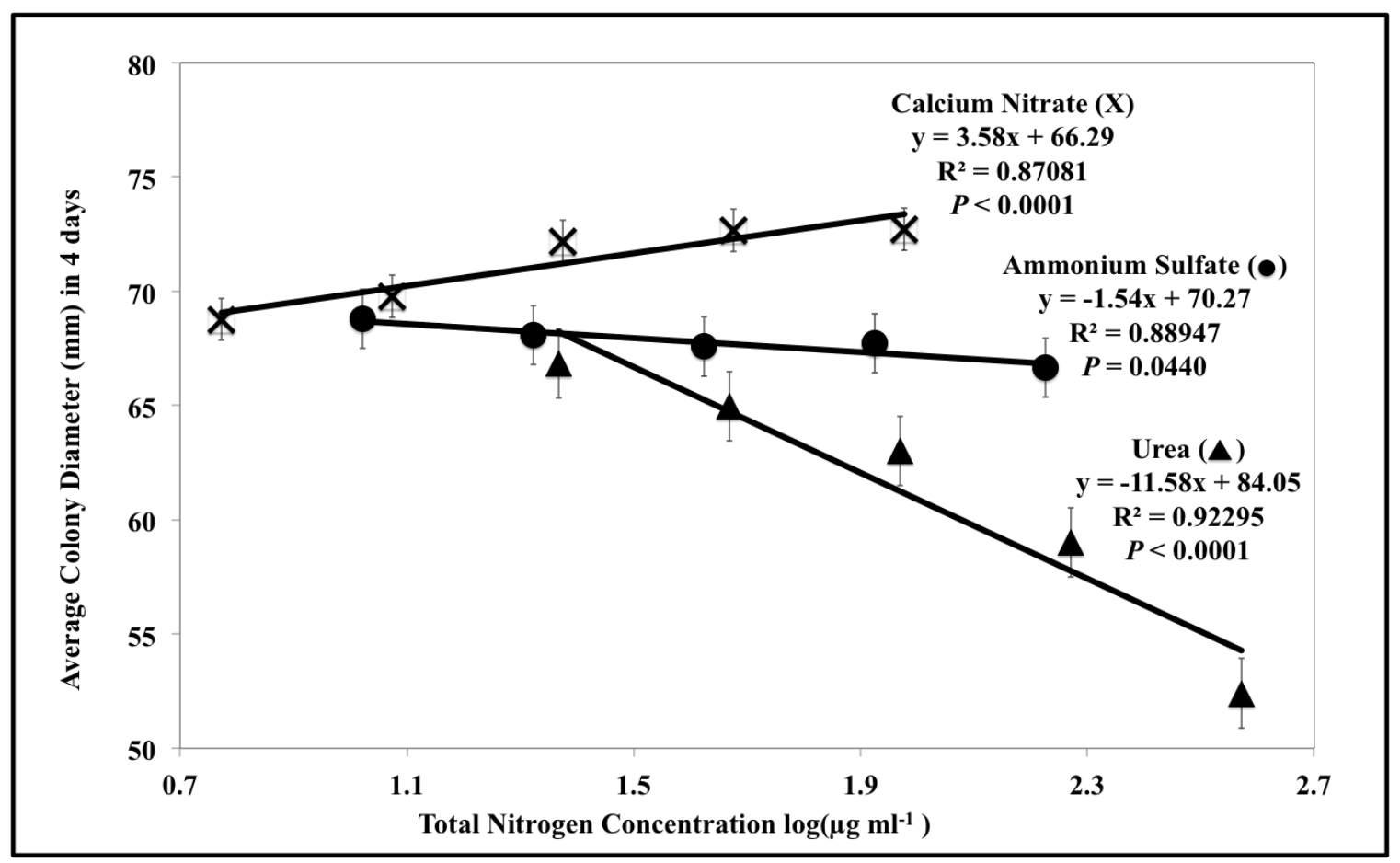

Figure 2.2 Radial large patch isolate growth on a basal medium buffered with $200 \mu \mathrm{g} \mathrm{ml}^{-}$ ${ }^{1}$ fumaric acid $\mathrm{pH}$ buffer and amended with either calcium nitrate, ammonium sulfate, or urea. Means are averaged across all isolates. Error bars represent the standard error of the mean. 


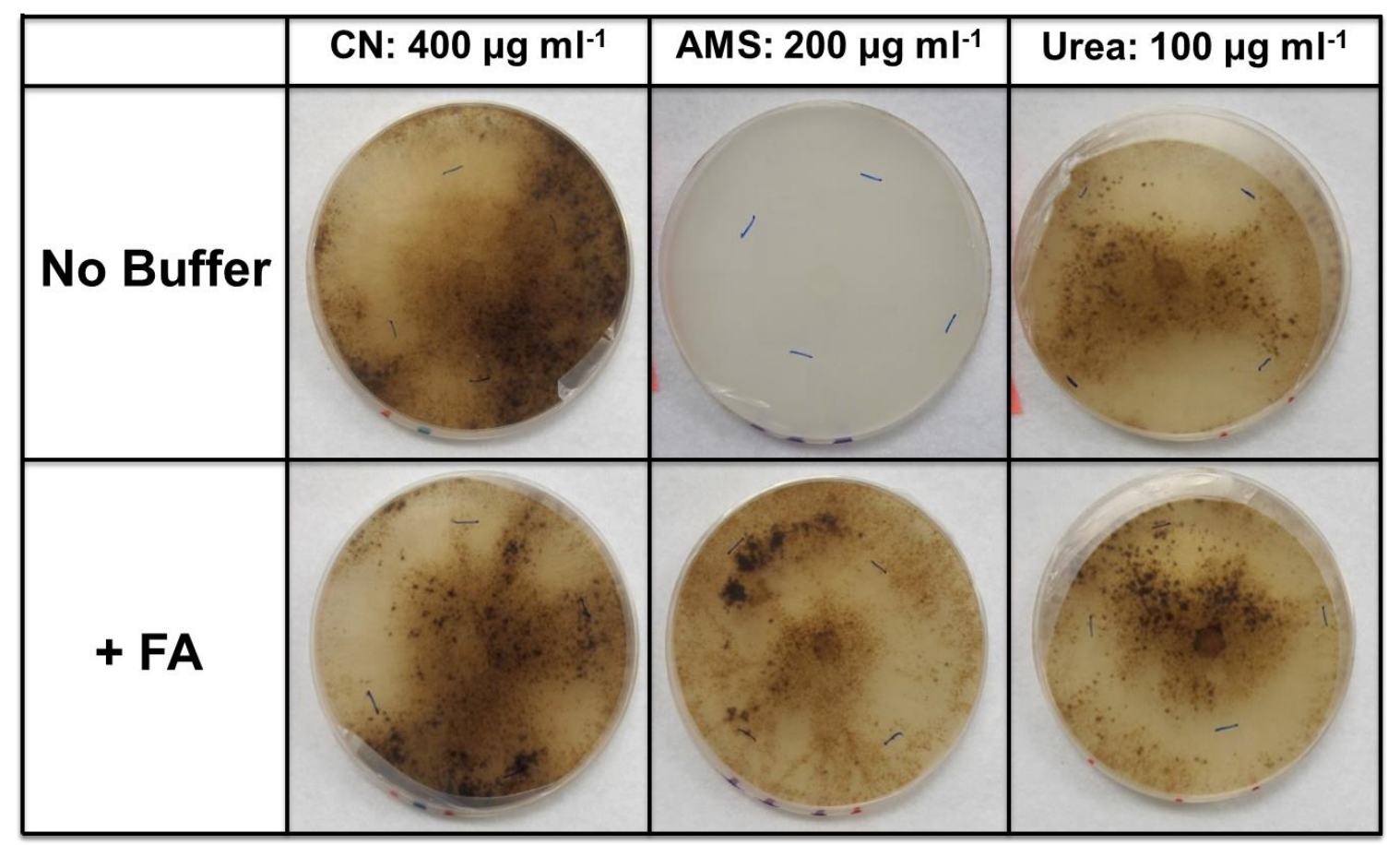

Figure 2.3 Morphology of $R$. solani AG 2-2 LP on different nitrogen media with and without fumaric acid buffer. Concentrations of each nitrogen source are approximately equal $\left(\sim 42 \mu \mathrm{g} \mathrm{N} \mathrm{ml}^{-1}\right)$. CN=Calcium Nitrate, AMS = Ammonium Sulfate. 


\section{CHAPTER 3}

Impact of nitrogen application timing, nitrogen source, and a single fungicide application on large patch of zoysiagrass

To be submitted to Crop Science 
Impact of nitrogen application timing, nitrogen source, and a single fungicide application on large patch of zoysiagrass

\begin{abstract}
Large patch is the most limiting disease on 'Meyer' zoysiagrass fairways, tees, and lawns in the United States transition zone. A disease management strategy integrating cultural practices would be preferable to multiple fungicide applications. This experiment examined the effects of nitrogen application timing, nitrogen source, and a single fungicide application on disease severity. Calcium nitrate, urea, and ammonium sulfate were examined for effects on large patch in a greenhouse study. In the field these nitrogen sources were applied in spring, fall, and spring and fall when 5-day average 5$\mathrm{cm}$ soil temperatures reached $18^{\circ} \mathrm{C}$, and compared to summer-only fertilizer treatments. A spring-applied polymer-coated urea was also examined at $144 \mathrm{~kg} \mathrm{~N} \mathrm{ha}^{-1}$. Duplicate plots received one spring application of tebuconazole at $0.824 \mathrm{~kg}$ ai ha ${ }^{-1}$. Nitrogen source did not impact pathogen infection or disease severity. Spring nitrogen applications were most consistent at reducing disease severity compared to summer-only applications of nitrogen. Spring tebuconazole applications did not prevent large patch, but reduced overall severity. A management strategy incorporating nitrogen applications in the spring could be effective in decreasing large patch outbreaks in the field compared to only applying nitrogen in the summer.
\end{abstract}




\section{Introduction}

'Meyer' zoysiagrass (Zoysia japonica Steud.) is favored for use on golf course fairways and tees in the upper United States transition zone due to its excellent traffic durability, low maintenance requirements, and cold hardiness (Christians 2007). Although zoysiagrass is relatively pest tolerant, large patch caused by the fungal pathogen Rhizoctonia solani Kühn AG 2-2 LP is the most limiting disease that affects zoysiagrass. The pathogen infects at the leaf sheath causing reddish-brown necrotic lesions, which can lead to basal sheath rot (Couch 1995). Large patch symptoms include matted orange or brown patches ranging from 3-25 feet or greater in diameter and bright orange patch margins known as "firing" during high disease activity. If severe enough, the disease can leave patches or rings of completely killed turf which are slow to recover and have reduced aesthetics and playability (Dunn and Diesburg 2004; Smiley et al. 2005). Large patch symptoms appear at the slowest, weakest periods of zoysiagrass growth when the turf is entering or exiting dormancy in the cool, wet periods during fall and spring (Couch 2000; Smiley et al. 2005). Current measures of disease control revolve around two to four fungicide applications per year split between the spring and fall months when symptoms normally develop (Vincelli and Munshaw 2014).

Large patch of warm-season turfgrasses and brown patch of cool-season turfgrasses are both caused by pathogens of the genus-species Rhizoctonia solani. However, the causal pathogens for each disease belong to different anastomosis groups (AGs), infect different hosts, and affect their respective hosts at different periods of time, indicating they are different pathogens altogether (Hyakumachi et al. 1998). Due to the similarities in pathogen taxonomy, research findings on brown patch management are often translated to similar management strategies for large patch. For example, excessive 
rates of nitrogen applied during brown patch activity in the summer are consistently linked to increased brown patch severity on cool-season grasses (Bloom and Couch 1960; Burpee 1995; Cutulle et al. 2014; Fidanza and Dernoeden 1996; Vincelli and Powell 1996; Watkins and Wit 1993). Consequently, nitrogen applications on warm-season grasses have been discouraged during spring and fall to decrease the chance of large patch outbreaks (Smiley et al. 2005). However, no research exists linking spring and fall timings of nitrogen to increased large patch incidence and only a few trials have focused on the response of large patch severity to fertilization during the infection period (Miller et al. 2016; Obasa et al. 2013). Green et al. (1994) found that summer urea rates did not impact large patch severity, and there was no significant difference in disease severity between summer-applied synthetic and natural nitrogen sources. A spring and fall urea application was associated with decreased large patch severity compared to summer standard urea applications (Obasa et al. 2013). In another study, separate fall and spring nitrogen applications did not increase large patch severity compared to summer-only nitrogen applications (Miller et al. 2016). These discoveries contradict previous notions associating nitrogen applications during large patch activity with increased disease severity.

Although nitrogen timing has been a focus of previous large patch management research, long-term studies focusing on nitrogen source have been limited (Miller et al. 2016). In previous research on $R$. solani AG 2-2 LP, ammonium sulfate-amended media $\left[\left(\mathrm{NH}_{4}\right)_{2} \mathrm{SO}_{4}\right]$ reduced pathogen growth and prevented fungal melanin production at high concentrations (Koehler and Miller 2017). Loss of melanin production in other AGs of R. solani reduced pathogenicity and lesion size on their respective host plants (Kim et al. 
2001; Sneh et al. 1989). If reduced melanin production limits $R$. solani infection, then exposure to ammonium sulfate applications during the infection period may also reduce large patch disease severity. Therefore, the goal of this research was to develop a large patch management strategy integrating nitrogen source and application timing to reduce the need for multiple fungicide applications on zoysiagrass.

\section{Materials and Methods}

\section{Rhizoctonia solani AG 2-2 LP infection potential after growth on nitrogen media}

A greenhouse experiment was designed to evaluate the impact of nitrogen source on in vivo infection of $R$. solani AG 2-2 LP. 'Meyer' zoysiagrass (Zoysia japonica Steud.) plants were established in greenhouse facilities at the University of Missouri in Columbia, Missouri. Zoysiagrass stolons were cut into sprigs containing two to three nodes. The cut sprigs were then surface sterilized in a $1 \% \mathrm{NaOCl}$ solution for one minute and rinsed twice in deionized water. Five sprigs were placed into $3.8 \mathrm{~cm}$ diameter ConeTainers (Steuwe \& Sons, Inc., Corvallis, OR) containing peat moss-based growth media (PRO-MIX BX; Premier Tech Horticulture, Rivière-du-Loup, QC, Canada) and grown in a greenhouse room maintained at $27^{\circ} \mathrm{C}$ for eight weeks. Plants were maintained with 24 kg N/ha of 20-20-20 N-P-K (Jack's Professional water-soluble fertilizer; JR Peters, Inc., Allentown, PA) once per week until four weeks prior to inoculation. Plants were watered as needed to prevent drought symptoms. One week prior to inoculation, Cone-Tainers were culled to contain a single plant with two tillers. Plants were placed into a growth chamber maintained at $23^{\circ} \mathrm{C}$ with a 12-hour day/night photoperiod five days prior to inoculation and throughout the completion of the experiment. Humidity in the growth chamber was maintained using a humidifier (707 Model; Herrmidifier, Sanford, NC) to 
achieve a nighttime relative humidity of greater than $90 \%$, monitored with a temperature and humidity data-logger (EL-USB-2-LCD; Lascar Electronics, Erie, PA). The humidifier was run on alternating 30 minute intervals between 2000 and 0800 each day. No extra irrigation was applied through the course of the experiment.

Basal media from a previous study on $R$. solani AG 2-2 LP mycelial growth and morphology was used to prepare inoculum treatments (Koehler and Miller 2017; He and Suzuki 2003). Media was amended with $42 \mu \mathrm{g} \mathrm{ml}^{-1}$ nitrogen of either urea, calcium nitrate, ammonium sulfate, or ammonium sulfate plus the fumaric acid buffer ( $200 \mu \mathrm{g}$ $\mathrm{ml}^{-1}$ ). Fumaric acid buffer was utilized to mitigate $\mathrm{pH}$ differences in ammonium sulfate amended media, and reduce melanin inhibition in the culture (Koehler and Miller 2017). Sterilized cellophane $(65 \mathrm{~mm} \times 65 \mathrm{~mm})$ was placed on top of the media after it was solidified. A $9 \mathrm{~mm}$ core of water agar containing actively growing $R$. solani AG 2-2 LP mycelium from a single isolate was then placed on the cellophane for each equal concentration nitrogen media and also PDA. After three weeks, mycelium was scraped from the cellophane and rolled into a mycelial ball approximately $0.5 \mathrm{~cm}$ in diameter. Mycelium harvested from potato dextrose agar (PDA; Difco Laboratories, Detroit, MI) and a $0.5 \mathrm{~cm}$ diameter plug of sterile PDA containing no mycelial growth were used as controls.

The experiment was arranged in a completely randomized design with four replications. The six inoculum media served as treatments - urea, calcium nitrate, ammonium sulfate, ammonium sulfate with fumaric acid, PDA or a PDA plug with no mycelial growth. Inoculation procedures were adapted from Park et al. (2008). Briefly, a mycelial ball or uninfested PDA plug was placed between the two tillers, which were 
then wrapped together using sterile aluminum foil. Cone-Tainers were covered with a transparent plastic bag to create a microclimate suitable for infection. After four days, the bag and foil were removed. Plants were monitored for disease for 32 days postinoculation. The entire experiment was repeated three times.

Disease incidence was assessed as a percentage of visually symptomatic tillers with ratings of $0 \%$ for no symptoms, $50 \%$ for one symptomatic tiller, or $100 \%$ for both tillers showing symptoms. Symptom initiation was assessed as the number of days postinoculation when first visible symptoms were noted. If no symptoms were present on the final date, the plants were assessed a rating of 36 days. Disease severity was assessed as a visual estimation of the percentage of plant area affected. The area under disease progress curve (AUDPC) was calculated using the trapezoidal method: $\mathrm{AUDPC}=$

$\sum_{i=1}^{N_{i}} \frac{\left(y_{i}+y_{i+1}\right)}{2}\left(t_{i+1}-t_{i}\right)$ where $\mathrm{y}_{\mathrm{i}}=$ disease symptom percentage, and $\mathrm{t}_{\mathrm{i}}=$ time of the $i$ th rating (Madden et al. 2007; Shaner and Finney 1977). Least square means (LSMeans) of greenhouse disease ratings were subjected to analysis of variance using the PROC GLIMMIX procedure in SAS (version 9.3; SAS Institute. Cary, NC). Means were separated using Fisher's protected LSD $(\alpha=0.05)$.

\section{Nitrogen source impact on large patch severity in a controlled growth environment}

A second greenhouse experiment was conducted to examine the effects of nitrogen source on the development of large patch on zoysiagrass. Prior to initiation of the experiment in November 2016, dormant 'Meyer' zoysiagrass cores (8 cm diameter) were collected from the University of Missouri Turfgrass Research Center in Columbia, MO in areas with no large patch symptoms. These cores were thoroughly rinsed to 
remove excess soil from the thatch and roots. Whole cores were then surface sterilized in a $1 \% \mathrm{NaOCl}$ solution for one minute, then rinsed twice in deionized $\mathrm{H}_{2} \mathrm{O}$. Each core was placed in $10 \mathrm{~cm}$ diameter pots containing sterilized peat moss-based growth media (PROMIX BX; Premier Tech Horticulture, Rivière-du-Loup, QC, Canada). Greenup and establishment occurred for 16 weeks in a greenhouse maintained at $27^{\circ} \mathrm{C}$. Pots were maintained with $24 \mathrm{~kg} \mathrm{~N} \mathrm{ha}^{-1}$ of 20-20-20 N-P-K (Jack's Professional water-soluble fertilizer; JR Peters, Inc., Allentown, PA) once per week until four weeks prior to inoculation. Plants were watered as needed to prevent drought. Five days prior to inoculation, pots were placed into the growth chamber in the conditions described previously.

Four isolates of Rhizoctonia solani AG 2-2 LP were obtained from affected zoysiagrass sheaths from golf course fairways in Illinois, Kansas, and Missouri. Symptomatic sheaths were cut, rinsed of debris under water for 30 minutes, surface sterilized for 30 seconds using a $70 \%$ ethanol solution, and rinsed twice in sterile water. Sheath sections were then blotted dry and plated on water agar media (15g/L agar). Rhizoctonia solani AG 2-2 LP colonies that grew from the leaf sheaths were then transferred to full-strength potato dextrose agar $(15 \mathrm{~g} / \mathrm{L})$ amended with $50 \mathrm{mg} / \mathrm{L}$ each of chloramphenicol, streptomycin, and tetracycline (PDA+++). Isolates were maintained in a $-80^{\circ} \mathrm{C}$ freezer on filter paper, and grown for three weeks on PDA+++ prior to inoculum production. Ten cores (10 $\mathrm{mm}$ diameter) of the four isolates were added to a $2 \mathrm{~L}$ flask containing a sterilized mixture of $600 \mathrm{cc}$ of rye grain (Secale cereale L.), $400 \mathrm{ml}$ distilled water, and $5 \mathrm{ml}$ calcium carbonate $\left(\mathrm{CaCO}_{3}\right)$, and incubated at room temperature for three 
weeks. A control of sterile rye grain without $R$. solani growth was also created one day prior to inoculation.

The experiment was arranged in a $2 \times 3$ factorial design with three replications for each treatment for a total of 18 pots per experimental run. The entire experiment was repeated three times. For the inoculum factor, pots received either 10 infested rye grain or 10 sterile rye grain in three locations within the canopy for a total of 30 grains per pot. After inoculation a plastic bag was placed over the pot, twist-tied closed, and was placed inside the growth chamber. After one day, the pots were uncovered and treated with the urea (46-0-0), ammonium sulfate (21-0-0), or calcium nitrate (15.5-0-0) at a rate of $24 \mathrm{~kg}$ $\mathrm{ha}^{-1}$ applied at a $407 \mathrm{~L} \mathrm{ha}^{-1}$ water carrier volume. Pots remained uncovered in the growth chamber after fertility treatment and were rated for turf quality and disease severity every three to five days. Each experimental run was halted at 28 days post-inoculation. Turf quality was assessed on the NTEP scale of 1-9 with $1=$ entire pot area diseased, $6=$ commercially acceptable, and $9=$ excellent quality with no disease (National Turfgrass Evaluation Program 2012). Disease severity was measured as a visual estimation of the percent turf area affected by disease. The area under disease progress curve (AUDPC) was calculated using the trapezoidal method: AUDPC $=\sum_{i=1}^{N_{i}} \frac{\left(y_{i}+y_{i+1}\right)}{2}\left(t_{i+1}-t_{i}\right)$ where $\mathrm{y}_{\mathrm{i}}=$ disease symptom percentage, and $\mathrm{t}_{\mathrm{i}}=$ time of the $i$ th rating (Madden et al. 2007; Shaner and Finney 1977). Least square means (LSMeans) were subjected to analysis of variance using PROC GLIMMIX procedure in SAS (version 9.3; SAS Institute. Cary, NC). Means were separated using Fisher's protected LSD $(\alpha=0.05)$. 


\section{Nitrogen source, timing, and a single spring fungicide application}

A $3 \mathrm{yr}$ field experiment was conducted at the University of Missouri Turfgrass Research Center in Columbia, MO from September 2014 to June 2017. The research area consisted of 'Meyer' zoysiagrass (Zoysia japonica Steud.) established in 2011 on a Mexico silt loam (fine, smectitic, mesic Vertic Epiaqualf) with a pH of 5.6. Plots were maintained between 2 and $2.5 \mathrm{~cm}$ with weekly or bi-weekly mowing and were irrigated as needed. Irrigation water at this site has been recorded as slightly alkaline (7.5-8.0). Prior to trial initiation, all plots received $36 \mathrm{~kg} \mathrm{~N} \mathrm{ha}^{-1}$ of granular urea containing both urease and nitrification inhibitors (UMaxx; Koch Turf \& Ornamental, Wichita, KS) in June and July of 2014 and $36 \mathrm{~kg} \mathrm{~N} \mathrm{ha}^{-1}$ of urea in August 2014.

Plots were 1.5 by $3 \mathrm{~m}$ separated by a $0.3 \mathrm{~m}$ buffer, and arranged in a randomized complete block design with four replications and 27 total treatments. The three factors examined were nitrogen source, nitrogen application timing, and a single spring fungicide application. Nitrogen source treatments included urea (46-0-0; Lesco, Inc., Cleveland, $\mathrm{OH})$, calcium nitrate (15.5-0-0; Yara, Tampa, FL), ammonium sulfate (21-0-0; T and N, Inc, Foristell, MO), a polymer-coated urea (PCU) (43-0-0; Duration ${ }^{\circledR}$ CR 120-day; Koch Turf and Ornamental, Wichita, KS), and a no-fertility plot. Nitrogen timings included spring, fall, both spring and fall, and standard summer-only application timing (Table 3.1). Each plot of urea, calcium nitrate, or ammonium sulfate applications totaled $96 \mathrm{~kg}$ $\mathrm{N} \mathrm{ha}^{-1}$ per annum and nitrogen was applied at all previously listed timings. Soil temperatures were monitored using an in-ground data logger (HOBO U23 Pro V2; Onset Computer Corporation, Bourne, MA) placed at a depth 5-cm soil within the trial area. Spring and fall nitrogen applications occurred when the 5-cm soil temperature first 
reached a 5-day average of $18^{\circ} \mathrm{C}$. At those times, plots received $24 \mathrm{~kg} \mathrm{~N}$ ha $^{-1}$ of urea, calcium nitrate, or ammonium sulfate. These plots were then supplemented in June, July, and August with even applications of the same nitrogen source to reach a total of $96 \mathrm{~kg} \mathrm{~N}$ $\mathrm{ha}^{-1}$. The summer standard treatment of each nitrogen source was evenly split between June, July, and August. Polymer-coated urea was only applied once in the spring at the same $18^{\circ} \mathrm{C}$ soil temperature timing at a rate of $144 \mathrm{~kg} \mathrm{~N} \mathrm{ha}^{-1}$. All nitrogen applications were in granular form and shaken onto each plot by hand using shaker bottles. After fertility was applied, plots were irrigated with $0.08 \mathrm{~cm}$ water. Duplicates of all plots except the no-fertility plot received a single spring tebuconazole $\left(\right.$ Torque $^{\circledR}$, NuFarm, Alsip, IL) treatment of $0.82 \mathrm{~kg}$ ai ha ${ }^{-1}$ applied in $407 \mathrm{~L} \mathrm{ha}^{-1}$ water carrier. The application of tebuconazole occurred immediately after watering-in of spring fertility applications. The rates for this experiment were chosen based on surveys from golf course superintendents asking about preferred nitrogen fertility rates, fungicide application rates, and water carrier volume (data not shown).

Inoculum for each plot was prepared using the rye grain inoculum procedure as described above with the same four isolates plus one additional isolate. Each plot was inoculated at two points arranged evenly in the center of each plot with $25 \mathrm{ml}$ of $R$. solani infested rye grain on 30 September 2014. Inoculation points were covered with $6.45 \mathrm{~cm}^{2}$ square metal plates, which were removed the following spring on 14 April 2015. Soil analysis was conducted on 29 October 2015 and 15 June 2016. Ten cm soil samples were removed from two random points in each plot using an auger. Soil from each treatment repetition was consolidated into one single sample. Bulk soil analysis, including $\mathrm{pH}$, available phosphorus, potassium, calcium and magnesium, organic matter, 
neutralizable acidity, cation exchange capacity, and sulfur $\left(\mathrm{SO}_{4}-\mathrm{S}\right)$, was conducted at the University of Missouri Soil and Plant Testing Laboratory.

Disease severity and turfgrass quality were assessed every 7-10 days during large patch symptom occurrence in the spring and fall of 2015-2017. Disease severity was assessed as the visual estimation of the percent diseased area per plot. Turf quality was assessed on the NTEP scale of 1-9 with $1=$ entire plot area diseased, $6=$ commercially acceptable, and $9=$ excellent quality with no disease (National Turfgrass Evaluation Program 2012). Images of each plot were taken with a D90 Nikon DSLR camera (Nikon Inc., Mellville, NY) mounted on a $0.75 \mathrm{~m}$ horizontal section of a $3 \mathrm{~m}$ high monopod, so the camera was centered directly above the plot area. The camera was set to fully automatic mode, so aperture and shutter speed adjusted according to light conditions. Prior to image analysis, photos were manually cropped to plot borders and set to the same size $(1600 \times 1200$ pixels). Images were analyzed using SigmaScan Pro 5.0 (Systat Software, Inc., Point Richmond, CA) using image editing and batch analysis macros by Karcher and Richardson (2003). Pictures were analyzed for total percentage of nongreen (symptomatic) turf. Area under non-green cover curve (AUNGCC) and area under disease progress curve based on visual disease estimation (AUDPC) were calculated using the trapezoidal method to obtain a single measured variable for total disease during each season: AUNGCC $=\sum_{i=1}^{N_{i}} \frac{\left(y_{i}+y_{i+1}\right)}{2}\left(t_{i+1}-t_{i}\right)$ where $\mathrm{y}_{\mathrm{i}}=$ non-green cover or disease percentage on a given date and $t_{i}=$ rating date (Madden et al. 2007; Shaner and Finney 1977). Least square means for percent visual disease ratings and digital image analysis were subjected to analysis of variance in PROC GLIMMIX (SAS v 9.3; SAS corporation, 
Cary, NC) and means were separated using Fisher's protected least significant difference (LSD). PROC REG was used to assess correlation of AUNGCC and AUDPC.

\section{Results}

\section{Nitrogen source predisposition impact on $R$. solani infection}

Media type significantly impacted disease incidence, date of first symptoms, and AUDPC (Table 3.2). Tillers inoculated with isolates grown on PDA had the highest disease incidence, were the earliest to show symptoms, and had the highest overall disease severity. No disease symptoms were noted on tillers that were inoculated with a non-infested core of PDA. No differences in disease incidence, date of first symptoms, or AUDPC were detected among nitrogen source treatments $(P>0.05)$. Although symptoms were present on tillers inoculated with ammonium sulfate + fumaric acidgrown mycelia, disease severity levels were not significantly different from nonsymptomatic tillers inoculated with non-infested media cores $(P=0.2122)$.

\section{Nitrogen source impact on large patch severity in a controlled environment}

No differences in disease severity or final turf quality were observed in sterile rye compared to infested rye grain-inoculated zoysiagrass $(P=0.1044)$ (Table 3.3). Final turfgrass quality was numerically higher for sterile rye grain inoculated zoysiagrass compared to infested rye-inoculated zoysiagrass, but both were still unacceptable (4.48 sterile vs 3.87 infested). Nitrogen source significantly impacted AUDPC values, but not final quality ratings. Urea-treated plants had lower AUDPC values than calcium-nitrate treated zoysiagrass inoculated with $R$. solani AG 2-2 LP (Figure 3.1). 


\section{Field Nitrogen Applications and a Single Fungicide}

Fall fertility only increased spring green-up in Spring $2016(P<0.05)$. The quality of the non-fertilized plot did not reach acceptable quality (> 6.0) and had poor stand density and color throughout the trial. The $\mathrm{pH}$ of all treatments was between 5.55.9 in October 2015 and between 5.6-5.9 in June 2016 with no differences in $\mathrm{pH}$ among nitrogen sources. Higher $\mathrm{SO}_{4}-\mathrm{S}$ levels were observed in plots treated with ammonium sulfate (range of 5.6 to $11.5 \mathrm{ppm} \mathrm{SO}_{4}-\mathrm{S}$ ) compared to calcium nitrate, urea, $\mathrm{PCU}$, or nofertility (range of 4.1 to $4.6 \mathrm{ppm} \mathrm{SO}_{4}-\mathrm{S}$ ).

Visual AUDPC correlated well with digital AUNGCC in this study $\left(\mathrm{r}^{2}=0.7982\right.$; $P<0.0001)$ (Figure 3.2). There were significant differences between seasons $(P<$ 0.0001); therefore each season was analyzed separately. Fall applications in 2014 did not significantly decrease disease severity compared to summer applications made prior to trial initiation $(P>0.05)$. In Fall 2015, drought weather severely limited disease outbreaks and zoysiagrass also entered into dormancy early as a result.

Large patch symptoms were present on the date of spring fungicide applications in all three years of the study. Spring fungicide factor significantly $(P<0.05)$ reduced visual and digital symptoms on rating dates at the peak of disease and both AUNGCC and AUDPC in spring 2015, spring 2016, and fall 2016 (Table 3.4). There was not a significant difference in disease between tebuconazole-treated and untreated plots in spring 2017. The timing*fungicide interactions for both visual ratings and digital image analysis (DIA) was only significant in spring 2017. However, there were notable differences between specific nitrogen application timings when separated from their tebuconazole treated duplicates (Figures 3.3-3.10). In all four severe disease outbreaks, 
summer fertility without tebuconazole had the highest AUDPC and AUNGCC values when not treated with a fungicide. These values were also significantly higher in all years when compared to those of summer-only plus tebuconazole plots. Fall nitrogen applications with or without tebuconazole significantly decreased disease values in spring 2016 and fall 2016. In spring 2015, the fall nitrogen application without tebuconazole was not significantly different in disease severity levels than the summer-only fertility without tebuconazole. In spring 2017, disease levels of plots treated with fall nitrogen applications plus tebuconazole were not significantly different than the summer-only fertility plots without tebuconazole. Spring nitrogen applications with and without tebuconazole were not significantly different from each other in any season and had significantly lower disease levels in spring 2015, fall 2016, and spring 2017. Plots that received both fall and spring nitrogen applications without tebuconazole did not significantly differ in disease severity levels compared to summer-only fertility plots without tebuconazole in spring 2016, fall 2016, and spring 2017. Fall and spring nitrogen applications with tebuconazole had the lowest disease severity levels in every season.

Nitrogen source and application timing did not interact in any season, but nitrogen source, application timing, and the tebuconazole application did have an interaction in spring 2017 (Table 3.4). Visual and digital disease severity between any nitrogen source treatments when tebuconazole was not applied, including non-fertilized plots, were not significantly different (Table 3.5). In spring 2016 and 2017, turfgrass quality was higher in PCU-treated plots compared to all other nitrogen source treatments (Table 3.6). 


\section{Discussion}

Unlike previous studies regarding melanin impact on disease severity of $R$. solani (Kim et al. 2001; Sneh et al. 1989), large patch severity on zoysiagrass was not significantly different between non-pigmented mycelium grown on ammonium sulfateamended media and brown, pigmented mycelium grown on calcium nitrate-, urea-, and fumaric acid buffered ammonium sulfate-amended media. Melanin inhibition of $R$. solani cultures in vitro by ammonium sulfate amended media may be caused by a rapid $\mathrm{pH}$ decrease. When transferred back to PDA $(\mathrm{pH}=5.5)$, isolates resume melanin production and cultures appeared dark brown like the wild type (Koehler and Miller 2017). Similarly, large patch isolates may resume normal melanin production in in planta greenhouse conditions, which were not $\mathrm{pH}$ limiting. In a nutrient-deficient environment, Rhizoctonia pathogenicity is greatly restricted but may be recovered after assimilating nutrients from a nutrient-sufficient environment (Weinhold et al. 1972). In this experiment, melanin production in ammonium sulfate-grown isolates may have resumed when introduced to a new, more suitable growth environment and susceptible host, allowing for pathogen infection and symptom development.

Surprisingly, disease severity on plants inoculated with mycelium grown on buffered ammonium sulfate was lower than non-buffered ammonium sulfate, and not statistically different from non-inoculated plants. This result contrasts the original hypothesis that fumaric acid would buffer $\mathrm{pH}$, allow for melanin pigmentation by the pathogen, and subsequently increase disease severity and infection. Multiple AGs of $R$. solani have been shown to produce fumaric acid, which has been characterized as a phytotoxin (Hyakumachi et al. 1980; Mirocha et al. 1961), but has not been previously 
linked to increased pathogenicity of $R$. solani (Hyakumachi et al. 1980). Accumulation of fumaric acid and other organic acids in the plant apoplast may aid in production of reactive oxidation species, increasing plant defenses against pathogens ( $\mathrm{O}^{\prime}$ Brien et al. 2012a; O’Brien et al. 2012b). In this study, fumaric acid present on the mycelial ball may induce a plant defense response rather than increasing infection capabilities of the fungus. Fumaric acid treatments to zoysiagrass could be investigated as a potential means of increasing plant defenses and reducing disease.

In the greenhouse fertility experiment there was not a significant difference between sterile and infested rye inoculum in either disease severity or quality, indicating a potential flaw in the initial sterilization procedure. Growth chamber conditions were favorable for pathogen infection and not ideal for optimal zoysiagrass growth, causing a decline in quality by the final rating date. Additionally, $R$. solani may have been present in the dense thatch layer of the zoysiagrass prior to initiation of the experiment.

Although no initial symptoms were present on the zoysiagrass when extracted from the field and during greenhouse establishment, $R$. solani may have survived the surface sterilization procedure and caused symptoms the zoysiagrass when conditions were ideal for pathogen growth and infection. Prior research has shown Rhizoctonia solani can still be present on zoysiagrass even when asymptomatic (Aoyagi et al. 1998). The methods in this experiment were used due to difficulty establishing 'Meyer' zoysiagrass using sterile sprigs with enough density to accurately differentiate disease severity. Ideally, a method of washing to fully penetrate the thatch layer or starting zoysiagrass growth from sterile stolons should be used for future experiments. 
A single spring tebuconazole application was effective in decreasing large patch severity in Spring 2015, 2016, and in Fall 2016. However, large patch outbreaks began prior to the $18^{\circ} \mathrm{C} 5$-day average 5 -cm soil temperature spring application timing in all three years, with the most severe outbreak occurring in Spring 2017. If relying on a single spring fungicide application, preventative treatments should occur prior to $18^{\circ} \mathrm{C}$ soil temperatures for more effective large patch control.

Nitrogen application timing impacted large patch severity, with plots treated with summer-only nitrogen applications having the highest disease severity in every season of the study. This result supports previous research indicating nitrogen applications during the large patch infection period do not increase large patch severity and may in fact reduce it (Miller et al. 2016; Obasa et al. 2013). Nitrogen applications when plant metabolism is slowed by suboptimal temperatures may increase foliar growth and allow zoysiagrass to outgrow pathogen infection. Spring nitrogen applications were most consistent in decreasing disease severity both with and without a fungicide application. Therefore, it is recommended to incorporate an early spring fertility application at the $18^{\circ} \mathrm{C}$ soil temperature threshold with a normal summer nitrogen regimen.

Plots treated with PCU (without tebuconazole) were the only plots to reach commercially acceptable quality during the peak large patch epidemic in spring 2016. This outbreak, approximately one month after application, was accompanied PCU-treated plots had dark-green turf cover after approximately one month post-application compared to the other treatments. This color difference was also noted in other seasons, but high disease severity dominated the overall quality ratings. Controlled-release nitrogen sources may release $80 \%$ of stored nitrogen after 35 days when not worked into 
the soil (Ransom 2014). Because PCU was applied at a higher initial rate compared to the quick-release nitrogen ( $\left.144 \mathrm{~kg} \mathrm{ha}^{-1} \mathrm{vs} 24 \mathrm{~kg} \mathrm{ha}^{-1}\right)$, a rate effect could be increasing overall quality and allowing for increased foliar growth that outpaces symptom development.

There were no significant differences in visual or digital disease severity ratings between any of the nitrogen sources. A prior experiment (Miller et al. 2016) found ammonium sulfate-treated plots had lower disease severity than urea summer-applied plots in Missouri and also lower disease severity compared to both calcium nitrate- and urea-treated plots in Kansas. In those cases, higher initial ammonium sulfate rates $(36 \mathrm{~kg}$ $\mathrm{ha}^{-1}$ ) may be a factor in reducing disease. In a previous laboratory experiment, pathogen growth on ammonium sulfate media at or above $84 \mu \mathrm{g} \mathrm{N} \mathrm{ml}^{-1}$ made the media more acidic (Koehler and Miller 2017). High laboratory urea rates also decreased pathogen growth. The field rates in this experiment of $24 \mathrm{~kg} \mathrm{~N} \mathrm{ha}^{-1}$ measured at 5-cm depth is only equivalent to $49 \mu \mathrm{g} \mathrm{N} \mathrm{ml}^{-1}$. Although high urea rates are not linked to changes in large patch severity, ammonium volatilization may prevent higher urea rates from affecting large patch outbreaks (Green et al. 1994). Increasing the rates of spring or fall ammonium sulfate applications, or applying in a spray concentrate may yield a more acidic, and disease suppressing environment depending on underlying factors of thatch composition, soil texture, and buffering capacity. Future experiments should focus on assessment of increased rates of spring-applied ammonium sulfate on large patch severity and turfgrass quality. 


\section{Literature Cited}

Aoyagi, T., Kageyama, K., and Hyakumachi, M. 1998. Characterization and survival of Rhizoctonia solani AG2-2 LP associated with large patch disease of zoysia grass. Plant Disease 82:857-863.

Bloom, J. R., and Couch, H. B. 1960. Influence of environment on disease of turfgrasses. I. Effect of nutrition, pH, and soil moisture on Rhizoctonia brown patch. Phytopathology 50.

Burpee, L. L. 1995. Interactions among mowing height, nitrogen fertility, and cultivar affect the severity of Rhizoctonia blight of tall fescue. Plant Disease 79:721-726.

Christians, N. 2007. Fundamentals of Turfgrass Management. 3rd ed. John Wiley \& Sons, Inc, Hoboken, NJ.

Couch, H. B. 1995. Diseases of Turfgrasses. Third ed. Krieger Publishing Company, Malabar, FL.

Couch, H. B. 2000. The Turfgrass Disease Handbook. Krieger Publishing Company, Malabar, FL.

Cutulle, M., Derr, J., McCall, D., Nichols, A., and Horvath, B. 2014. Effect of mowing height and fertility on bermudagrass (Cynodon dactylon) encroachment and brown patch severity in tall fescue. Weed Technology 28:225-232.

Dunn, J., and Diesburg, K. 2004. Turf Management in The Transition Zone. 1st ed. John Wiley \& Sons, Inc., Hoboken, NJ.

Fidanza, M. A., and Dernoeden, P. H. 1996. Brown patch severity in perennial ryegrass as influenced by irrigation, fungicide, and fertilizers. Crop Sci. 36:1631-1638.

Green, D., Fry, J., Pair, J., and Tisserat, N. 1994. Influence of management practices on Rhizoctonia large patch disease in zoysiagrass. HortScience 29:186-188.

He, X.M. and A. Suzuki. 2003. Effect of nitrogen resources and $\mathrm{pH}$ on growth and fruit body formation of Coprinopsis phlyctidospora. Fungal Diversity 12: 35-44.

Hyakumachi, M., Kobayashi, K., and Ui, T. 1980. Production of Fumaric Acid by Rhizoctonia solani. Japanese Journal of Phytopathology 46:121-125.

Hyakumachi, M., Mushika, T., Ogiso, Y., Toda, T., Kageyama, K., and Tsuge, T. 1998. Characterization of a new cultural type (LP) of Rhizoctonia solani AG2 2 isolated from warm season turfgrasses, and its genetic differentiation from other cultural types. Plant Pathology 47:1-9.

Karcher, D. E., and Richardson, M. D. 2003. Quantifying turfgrass color using digital image analysis. Crop Science 43:943-951. 
Kim, H. T., Chung, Y. R., and Cho, K. Y. 2001. Mycelial melanization of Rhizoctonia solani AG1 affecting pathogenicity in rice. The Plant Pathology Journal 17:210215.

Koehler, J. F., and Miller, G. L. 2017. Impact of nitrogen source and a pH buffer on the in vitro growth and morphology of Rhizoctonia solani AG 2-2 LP. Intl. Turfgrass Soc. Res. J 13:In Press.

Madden, L. V., Hughes, G., and Bosch, F. 2007. The study of plant disease epidemics. American Phytopathological Society (APS Press).

Miller, G. L., Earlywine, D. T., Braun, R., Fry, J. D., and Kennelly, M. M. 2016. Influence of Nitrogen Source and Application Timing on Large Patch of Zoysiagrass. Crop, Forage \& Turfgrass Management 2.

Mirocha, C., Wilson, E., and DeVay, J. 1961. Role of fumaric acid in hull rot disease of almond. Phytopathology 51:851-860.

National Turfgrass Evaluation Program. 2012. National Zoysiagrass Test: 2007-2012 data. Beltsville, MD.

O’Brien, J. A., Daudi, A., Butt, V. S., and Bolwell, G. P. 2012a. Reactive oxygen species and their role in plant defence and cell wall metabolism. Planta 236:765-779.

O'Brien, J. A., Daudi, A., Finch, P., Butt, V. S., Whitelegge, J. P., Souda, P., Ausubel, F. M., and Bolwell, G. P. 2012b. A peroxidase-dependent apoplastic oxidative burst in cultured Arabidopsis cells functions in MAMP-elicited defense. Plant Physiology 158:2013-2027.

Obasa, K., Fry, J., Bremer, D., John, R. S., and Kennelly, M. 2013. Effect of cultivation and timing of nitrogen fertilization on large patch disease of zoysiagrass. Plant Disease 97:1075-1081.

Park, D. S., Sayler, R. J., Hong, Y. G., Nam, M. H., and Yang, Y. 2008. A method for inoculation and evaluation of rice sheath blight disease. Plant Disease 92:25-29.

Ransom, C. J. 2014. Nitrogen Use Efficiency of Polymer-Coated Urea. All Theses and Dissertations. 3985.

Shaner, G., and Finney, R. 1977. The effect of nitrogen fertilization on the expression of slow-mildewing resistance in Knox wheat. Phytopathology 67:1051-1056.

Smiley, R. W., Dernoeden, P. H., and Clarke, B. B. 2005. Compendium of Turfgrass Diseases. 3rd ed. APS Press, St. Paul, MN.

Sneh, B., Ichielevich-Auster, M., and Shomer, I. 1989. Comparative anatomy of colonization of cotton hypocotyls and roots by virulent and hypovirulent isolates of Rhizoctonia solani. Canadian Journal of Botany 67:2142-2149. 
Vincelli, P., and Powell, A. 1996. Impact of mowing height and nitrogen fertility on brown patch of tall fescue. Biological and Cultural Control Tests for the Control of Plant Diseases 11:34.

Vincelli, P., and Munshaw, G. 2014. Chemical control of turfgrass diseases 2015.

Watkins, J., and Wit, L. 1993. Effect of nitrogen level and cutting height on brown patch severity, 1992. Biological and Cultural Control Tests for the Control of Plant Diseases 8:124.

Weinhold, A., Dodman, R., and Bowman, T. 1972. Influence of exogenous nutrition on virulence of Rhizoctonia solani. Phytopathology 62:278-281. 


\begin{tabular}{ccccc}
\hline & & \multicolumn{3}{c}{ Application Dates (DD MM YY) } \\
\hline Timing $^{\mathbf{a}}$ & $\begin{array}{c}\text { Nitrogen }^{\mathbf{b}} \\
\text { Sources }\end{array}$ & Year 1 $^{\mathbf{c}}$ & Year 2 & Year 3 \\
\hline $\begin{array}{c}\text { Summer } \\
\text { and }\end{array}$ & AMS, CN, U & 26 Jun 14 & 20 Jun 15 & 16 Jun 16 \\
Supplement & & 7 Jul 14 & 15 Jul 15 & 15 Jul 16 \\
Fall & AMS, CN, U & 15 Aug 14 & 18 Aug 15 & 18 Aug 16 \\
Spring & 16 Sept 14 & 5 Oct 15 & 4 Oct 16 \\
Fall+Spring & AMS, CN, U & 16 Sept 14 + 6 May 15 & 6 Oct 15 + 6 May 16 & 4 Oct 16 + 12 May 17 \\
\hline
\end{tabular}

a All timings are based on a $18^{\circ} \mathrm{C} 5$-day average soil temperature threshold measured at a 5-cm depth.

${ }^{b}$ Nitrogen sources in this trial for the listed timings were granular forms of ammonium sulfate (AMS), calcium nitrate $(\mathrm{CN})$, urea $(\mathrm{U})$, or polymer coated urea $(\mathrm{PCU})$. All spring and fall applications of AMS, $\mathrm{CN}$ and $\mathrm{U}$ received $24 \mathrm{~kg} \mathrm{~N} / \mathrm{ha}$ on the listed date(s). PCU was applied one time each spring at a rate of $144 \mathrm{~kg} \mathrm{~N} / \mathrm{ha}$.

${ }^{\mathrm{c}}$ Summer treatments for Year 1 were $36 \mathrm{~kg} \mathrm{~N} \mathrm{ha}^{-1}$ of urea containing inhibitors for both urease and nitrification in June and July of 2014 and $36 \mathrm{~kg} \mathrm{~N} \mathrm{ha}^{-1}$ of urea in August 2014.

${ }^{d}$ All AMS, CN, and U plots were supplemented in the summer to total $96 \mathrm{~kg} \mathrm{~N} / \mathrm{ha}$ per annum.

Table 3.1 Application dates for fall, spring, and summer nitrogen treatments. 


\begin{tabular}{cccc}
\hline Growth Medium $^{\mathrm{a}}$ & \left.${\text { Incidence }(\%)^{\mathrm{b}}}^{\text {First Symptoms }(\text { DPI }}\right)^{\mathrm{c}}$ & AUDPC $^{\mathrm{d}}$ \\
\hline PDA & $88 \mathrm{a}$ & $12 \mathrm{c}$ & $1313 \mathrm{a}$ \\
U & $42 \mathrm{~b}$ & $25 \mathrm{~b}$ & $428 \mathrm{~b}$ \\
CN & $50 \mathrm{~b}$ & $25 \mathrm{~b}$ & $452 \mathrm{~b}$ \\
AMS & $54 \mathrm{~b}$ & $24 \mathrm{~b}$ & $540 \mathrm{~b}$ \\
AMS + FA & $46 \mathrm{~b}$ & $28 \mathrm{~b}$ & $245 \mathrm{bc}$ \\
No Mycelium & $0 \mathrm{c}$ & $36 \mathrm{a}$ & $0 \mathrm{c}$ \\
\hline
\end{tabular}

${ }^{a}$ Large patch isolates were grown on either potato dextrose agar (PDA) or basal media containing $42 \mu \mathrm{g}$ $\mathrm{ml}^{-1} \mathrm{~N}$ equivalent of urea $(\mathrm{U})$, calcium nitrate $(\mathrm{CN})$, ammonium sulfate (AMS), or AMS with

$200 \mu \mathrm{g} \mathrm{ml}^{-1}$ fumaric acid (FA). A $0.5 \mathrm{~cm}$ core of PDA without mycelial growth was used as a negative control.

${ }^{\mathrm{b}}$ Incidence indicates the average percentage of zoysiagrass tillers that were symptomatic for large patch.

${ }^{\mathrm{c}}$ First symptoms are the recorded day post inoculation (DPI) when first symptoms were noted on a tiller. If both tillers were asymptomatic on the final rating date, they were assessed a 36 dpi rating.

${ }^{\mathrm{d}}$ AUDPC represents the total disease severity calculated over a given time period.

Table 3.2 Effects of growth media on infection potential of $R$. solani AG 2-2 LP. Incidence of disease is the percentage of single zoysiagrass tillers inoculated with a specific media type which are symptomatic for large patch. Values with the same letter in a column are not significantly different from each other according to Fisher's protected $\operatorname{LSD}(\alpha=0.05)$. 


\begin{tabular}{cccc}
\hline & & Final Quality $^{\mathrm{a}}$ & $\mathrm{AUDPC}^{\mathrm{b}}$ \\
\hline Effect & df & $\operatorname{Pr}>\mathrm{F}$ & $\operatorname{Pr}>\mathrm{F}$ \\
\hline Nitrogen Source & 2 & 0.121 & 0.028 \\
Inoculum & 1 & 0.104 & 0.177 \\
Nitrogen Source * Inoculum & 2 & 0.633 & 0.157 \\
\hline
\end{tabular}

${ }^{a}$ Quality ratings were on an NTEP scale of 1 to 9 and take into account turf density, color, and disease severity.

${ }^{\mathrm{b}}$ AUDPC represents the total disease severity calculated over a given time period.

Table 3.3 Effects of nitrogen fertility source and inoculum type on the quality and disease severity on zoysiagrass in a growth chamber. $P$-values were calculated using PROC GLIMMIX. 


\begin{tabular}{|c|c|c|c|c|c|c|c|c|c|}
\hline & & \multicolumn{8}{|c|}{ Individual rating dates ${ }^{\mathrm{a}}$} \\
\hline & & \multicolumn{2}{|c|}{ 9 Jun 15} & \multicolumn{2}{|c|}{10 Jun 16} & \multicolumn{2}{|c|}{11 Nov 16} & \multicolumn{2}{|c|}{16 Jun 17} \\
\hline & & Visual $^{\mathrm{b}}$ & DIA & Visual & DIA & Visual & DIA & Visual & DIA \\
\hline Effect $^{c}$ & $\mathrm{df}$ & $\operatorname{Pr}>\mathrm{F}$ & $\operatorname{Pr}>F$ & $\operatorname{Pr}>\mathrm{F}$ & $\operatorname{Pr}>\mathrm{F}$ & $\operatorname{Pr}>\mathrm{F}$ & $\operatorname{Pr}>\mathrm{F}$ & $\operatorname{Pr}>\mathrm{F}$ & $\operatorname{Pr}>\mathrm{F}$ \\
\hline NS & 2 & 0.996 & 0.959 & 0.447 & 0.037 & 0.310 & 0.117 & 0.923 & 0.522 \\
\hline Timing & 3 & 0.096 & 0.042 & 0.440 & 0.060 & 0.191 & 0.258 & 0.177 & 0.066 \\
\hline NS*Timing & 6 & 0.945 & 0.840 & 0.637 & 0.953 & 0.500 & 0.834 & 0.036 & 0.460 \\
\hline Fungicide & 1 & $<.0001$ & $<.0001$ & 0.002 & $<.0001$ & 0.015 & 0.002 & 0.153 & 0.060 \\
\hline NS*Fung & 2 & 0.950 & 0.994 & 0.861 & 0.553 & 0.552 & 0.749 & 0.659 & 0.701 \\
\hline Timing*Fung & 3 & 0.058 & 0.398 & 0.141 & 0.088 & 0.051 & 0.060 & 0.001 & 0.002 \\
\hline \multirow[t]{4}{*}{ NS*Timing*Fung } & 6 & 0.878 & 0.921 & 0.784 & 0.944 & 0.197 & 0.361 & 0.021 & 0.072 \\
\hline & & \multicolumn{8}{|c|}{ AUDPC } \\
\hline & & \multicolumn{2}{|c|}{ Spring 2015} & \multicolumn{2}{|c|}{ Spring 2016} & \multicolumn{2}{|c|}{ Fall 2016} & \multicolumn{2}{|c|}{ Spring 2017} \\
\hline & & Visual & DIA & Visual & DIA & Visual & DIA & Visual & DIA \\
\hline Effect & $\mathrm{df}$ & $\operatorname{Pr}>\mathrm{F}$ & $\operatorname{Pr}>F$ & $\operatorname{Pr}>\mathrm{F}$ & $\operatorname{Pr}>\mathrm{F}$ & $\operatorname{Pr}>\mathrm{F}$ & $\operatorname{Pr}>F$ & $\operatorname{Pr}>F$ & $\operatorname{Pr}>\mathrm{F}$ \\
\hline NS & 2 & 0.879 & 0.916 & 0.314 & 0.256 & 0.352 & 0.213 & 0.963 & 0.800 \\
\hline Timing & 3 & 0.260 & 0.017 & 0.491 & 0.202 & 0.087 & 0.095 & 0.222 & 0.196 \\
\hline NS*Timing & 6 & 0.736 & 0.927 & 0.709 & 0.889 & 0.579 & 0.857 & 0.047 & 0.113 \\
\hline Fungicide & 1 & $<.0001$ & $<.0001$ & 0.018 & 0.008 & 0.005 & 0.001 & 0.289 & 0.179 \\
\hline NS*Fung & 2 & 0.440 & 0.692 & 0.830 & 0.632 & 0.581 & 0.708 & 0.836 & 0.792 \\
\hline Timing*Fung & 3 & 0.141 & 0.336 & 0.146 & 0.370 & 0.054 & 0.104 & $<0.001$ & $<0.001$ \\
\hline NS*Timing*Fung & 6 & 0.860 & 0.891 & 0.846 & 0.895 & 0.199 & 0.388 & 0.006 & 0.014 \\
\hline
\end{tabular}

a Individual rating dates represents the date of highest large patch severity. AUDPC represents the total disease

severity calculated over a given time period.

${ }^{\mathrm{b}}$ Effects are compared between visual and digital image analysis (DIA).

${ }^{\mathrm{c}}$ Effects examined were nitrogen source (NS), timing, fungicide, and all interactions.

Table 3.4 Effects of nitrogen source, application timing, and a single fungicide application on large patch of zoysiagrass. $P$-values were calculated using PROC GLIMMIX. Bold values indicate significant main effects or interactions $(P<0.05)$ of treatments. 


\begin{tabular}{|c|c|c|c|c|c|c|c|c|c|}
\hline & & \multicolumn{8}{|c|}{ AUDPC $^{\mathrm{a}}$} \\
\hline & & \multicolumn{2}{|c|}{ Spring 2015} & \multicolumn{2}{|c|}{ Spring 2016} & \multicolumn{2}{|c|}{ Fall 2016} & \multicolumn{2}{|c|}{ Spring 2017} \\
\hline & & Visual $^{\mathrm{b}}$ & DIA & Visual & DIA & Visual & DIA & Visual & DIA \\
\hline Effect $^{c}$ & $\mathrm{df}$ & $\mathrm{Pr}>\mathrm{F}$ & $\mathrm{Pr}>\mathrm{F}$ & $\operatorname{Pr}>\mathrm{F}$ & $\mathrm{Pr}>\mathrm{F}$ & $\mathrm{Pr}>\mathrm{F}$ & $\mathrm{Pr}>\mathrm{F}$ & $\mathrm{Pr}>\mathrm{F}$ & $\mathrm{Pr}>\mathrm{F}$ \\
\hline NS & 4 & 0.758 & 0.726 & 0.314 & 0.270 & 0.773 & 0.488 & 0.854 & 0.477 \\
\hline
\end{tabular}

a AUDPC represents the total disease severity calculated over a given time period.

${ }^{\mathrm{b}}$ Effects are compared between visual and digital image analysis (DIA).

${ }^{c}$ Nitrogen source (NS) included ammonium sulfate, calcium nitrate, urea, polymer-coated urea, and the untreated control plot.

Table 3.5 Effect of nitrogen source on large patch severity. $P$-values were calculated using PROC GLIMMIX across all non-tebuconazole treated plots. 


\begin{tabular}{ccccc}
\hline \multirow{2}{*}{ Nitrogen Source $^{\mathrm{b}}$} & \multicolumn{4}{c}{ Average Quality Ratings ${ }^{\mathrm{a}}$} \\
\cline { 2 - 5 } & Spring 2015 & Spring 2016 & Fall 2016 & Spring 2017 $^{\text {Spring }}$ \\
\hline AMS & 5.1 & $5.0 \mathrm{~b}$ & 4.4 & $4.4 \mathrm{~b}$ \\
CN & 5.1 & $5.3 \mathrm{~b}$ & 4.0 & $4.7 \mathrm{ab}$ \\
U & 5.2 & $5.5 \mathrm{~b}$ & 4.8 & $4.7 \mathrm{ab}$ \\
PCU & 5.5 & $7.4 \mathrm{a}$ & 5.1 & $5.8 \mathrm{a}$ \\
No fertility & 5.1 & $5.5 \mathrm{~b}$ & 3.8 & $3.5 \mathrm{~b}$ \\
\hline
\end{tabular}

${ }^{\text {a }}$ Turfgrass quality was assessed on the NTEP scale of 1-9 with $1=$ entire plot area diseased, $6=$ commercially acceptable, and $9=$ excellent quality with no disease.

${ }^{b}$ Nitrogen sources were ammonium sulfate (AMS), calcium nitrate $(\mathrm{CN})$, urea $(\mathrm{U})$, polymer-coated urea (PCU), and a no fertility treatment.

Table 3.6 Effect nitrogen source on turfgrass quality. Means were separated for all nontebuconazole treated plots using Fisher's protected LSD with $\alpha=0.05$ significance. 


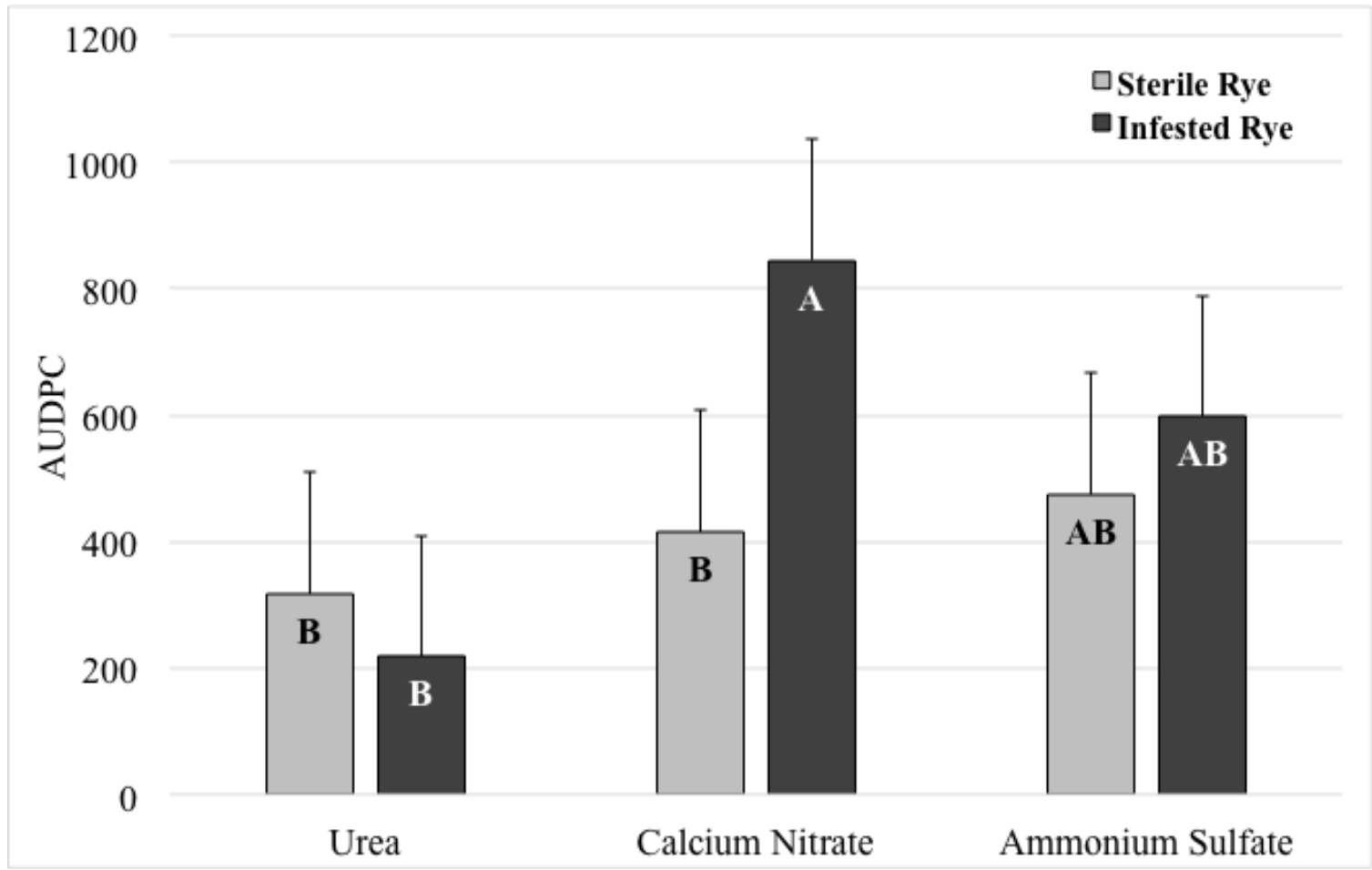

Figure 3.1. Disease severity of zoysiagrass in a greenhouse experiment after nitrogen fertility applications. AUDPC represents the total disease severity calculated over a given time period. Disease severity for plants inoculated with sterile, non-infested rye grain is indicated by the light-colored bars, while plants inoculated with large patch infested rye grain is indicated by dark colored bars. Bars with the same letters are not significantly different from each other according to Fisher's protected LSD $(P=0.05)$. Error bars represent the standard error of the mean. 


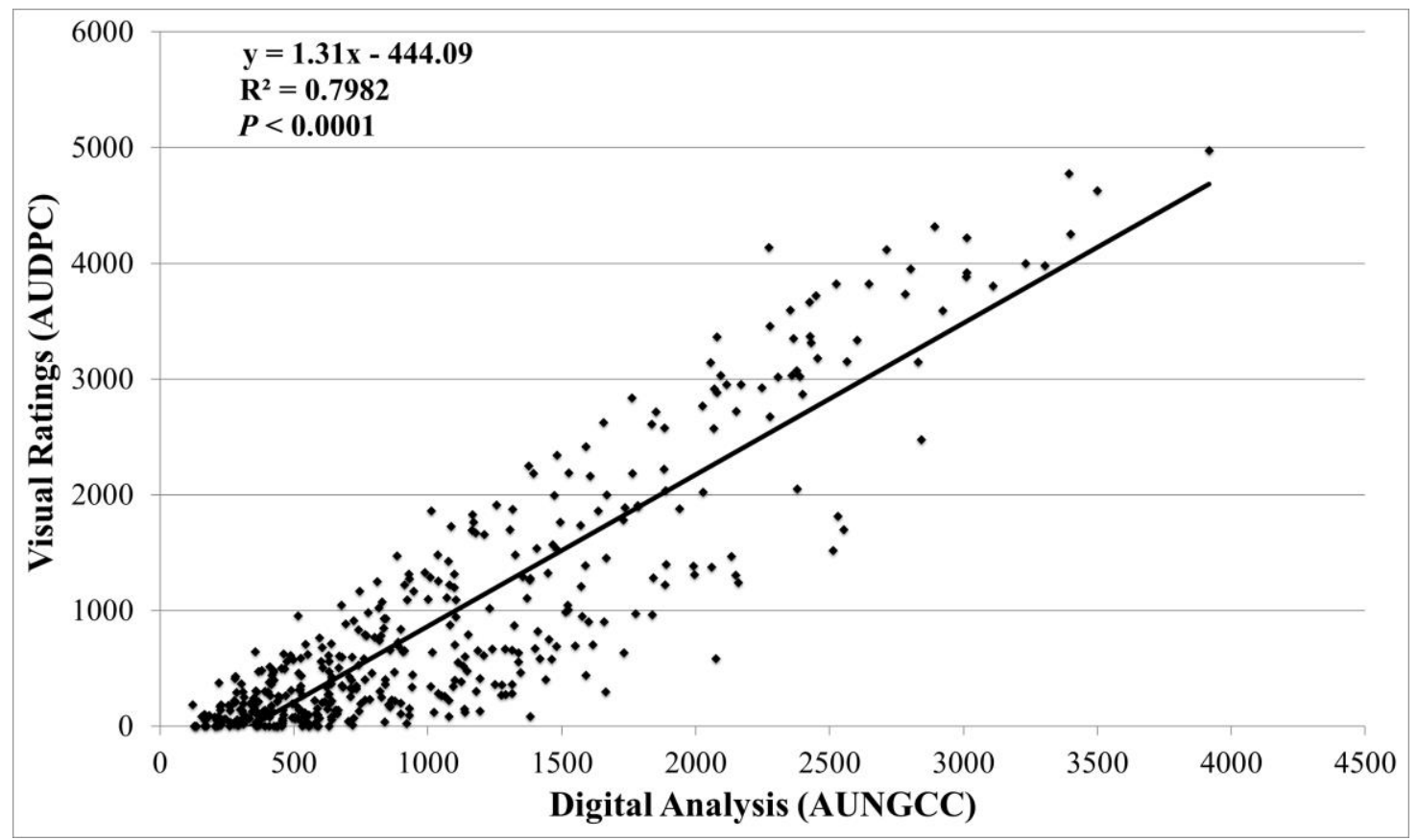

Figure 3.2 Regression analysis of AUDPC vs AUNGCC. P-values and $\mathrm{R}^{2}$ values were calculated using PROC REG. AUDPC represents the total visual disease severity over the disease period calculated using the trapezoidal method. AUNGCC represents the digitally analyzed non-green turf over the disease period calculated using the trapezoidal method. 


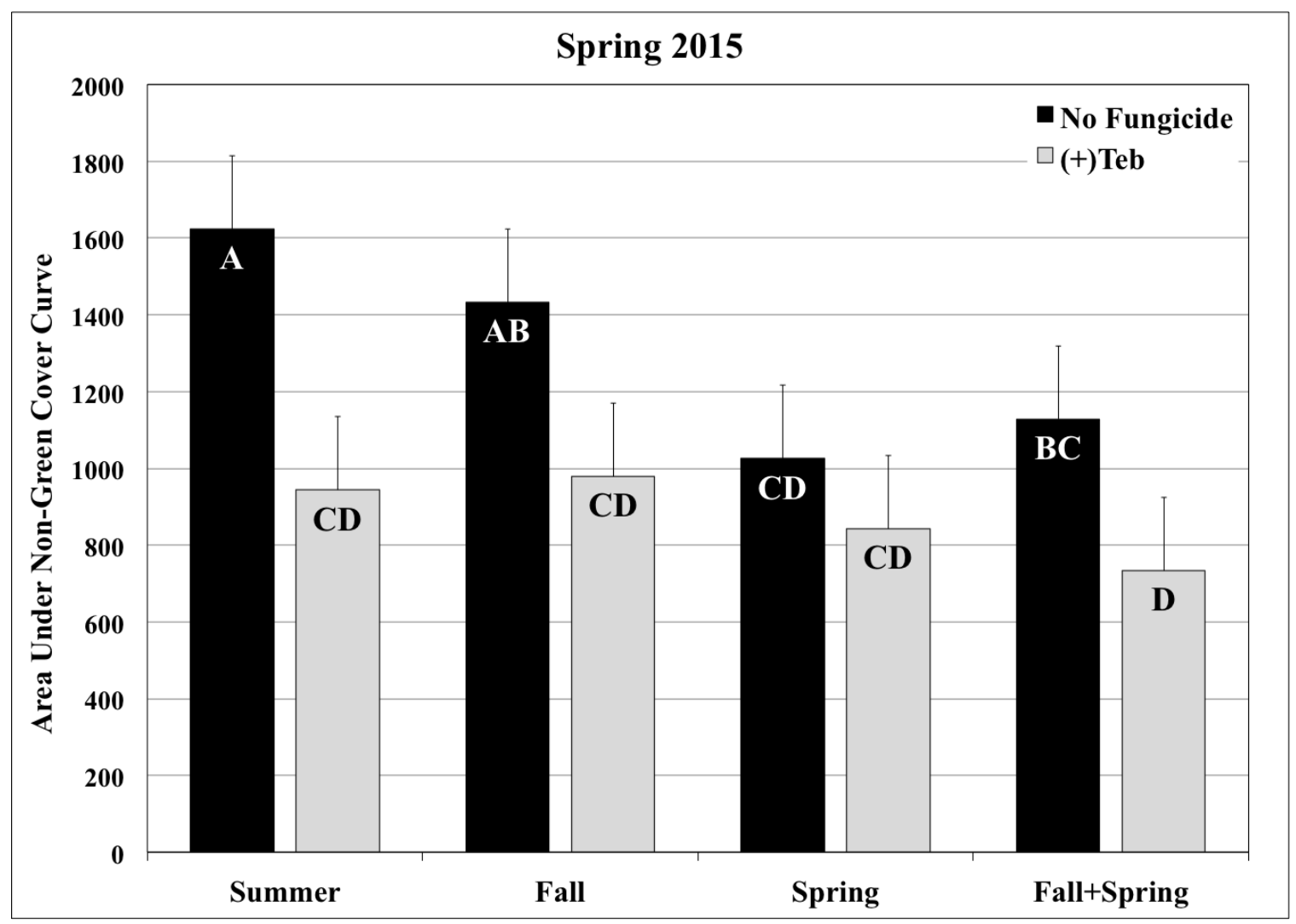

Figure 3.3 Effects of nitrogen application timing on non-green turf in A) Spring 2015, B) Spring 2016, C) Fall 2016, and D) Spring 2017. Means are averaged across all calcium nitrate, ammonium sulfate, and urea applications. AUNGCC represents the total non-green cover acquired through digital image analysis in Sigma Scan and calculated using the trapezoidal rule (Madden et al. 2007; Shaner and Finney 1977). Bars with the same letters are not significantly different from each other according to Fisher's protected LSD $(\alpha=0.05)$. Error bars represent the standard error of the mean. 


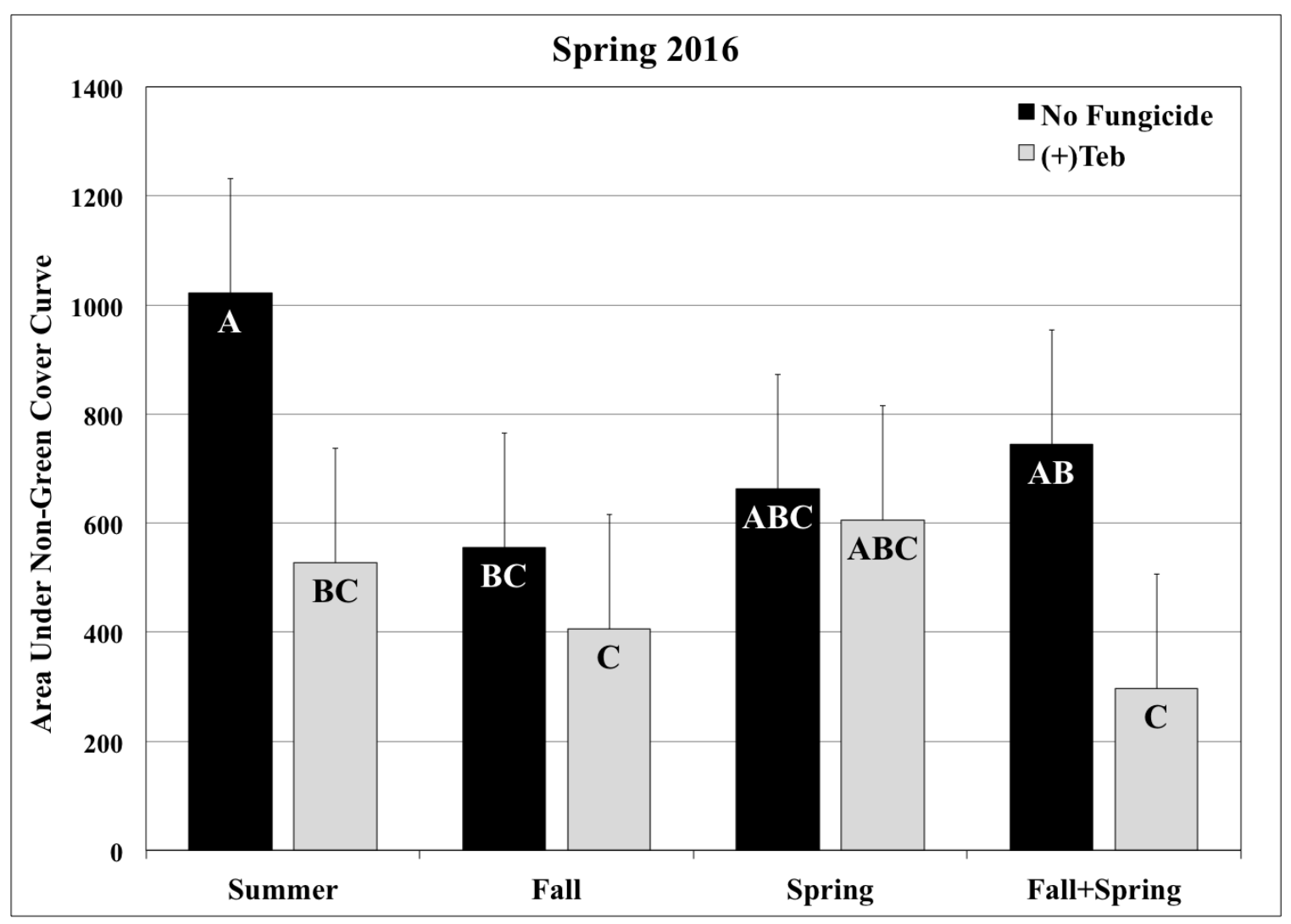

Figure 3.4 Effects of nitrogen application timing on non-green turf in Spring 2016. Means are averaged across all calcium nitrate, ammonium sulfate, and urea applications. AUNGCC represents the total non-green cover acquired through digital image analysis in Sigma Scan and calculated using the trapezoidal rule (Madden et al. 2007; Shaner and Finney 1977). Bars with the same letters are not significantly different from each other according to Fisher's protected LSD $(\alpha=0.05)$. Error bars represent the standard error of the mean. 


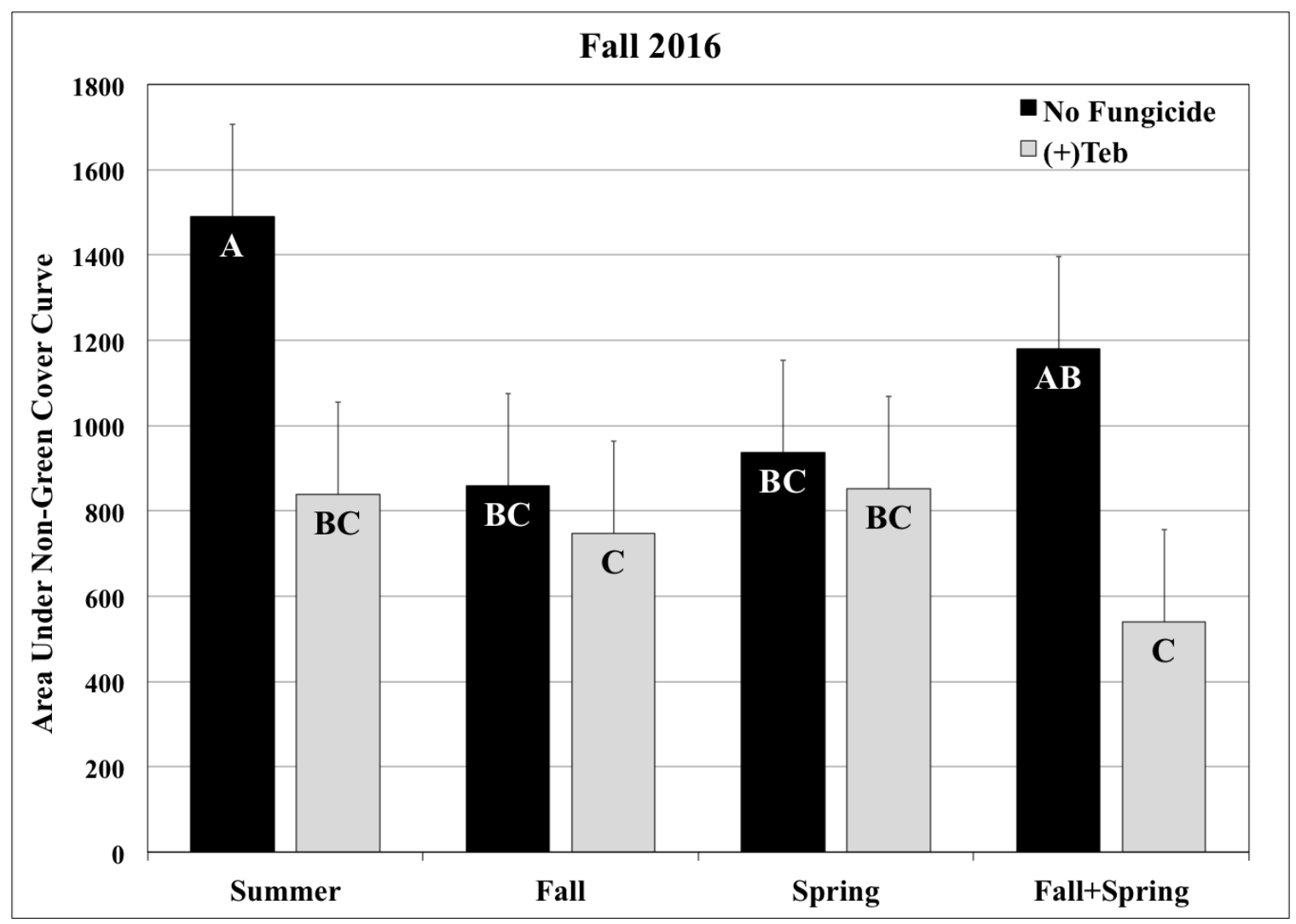

Figure 3.5 Effects of nitrogen application timing on non-green turf in Fall 2016. Means are averaged across all calcium nitrate, ammonium sulfate, and urea applications.

AUNGCC represents the total non-green cover acquired through digital image analysis in Sigma Scan and calculated using the trapezoidal rule (Madden et al. 2007; Shaner and Finney 1977). Bars with the same letters are not significantly different from each other according to Fisher's protected LSD $(\alpha=0.05)$. Error bars represent the standard error of the mean. 


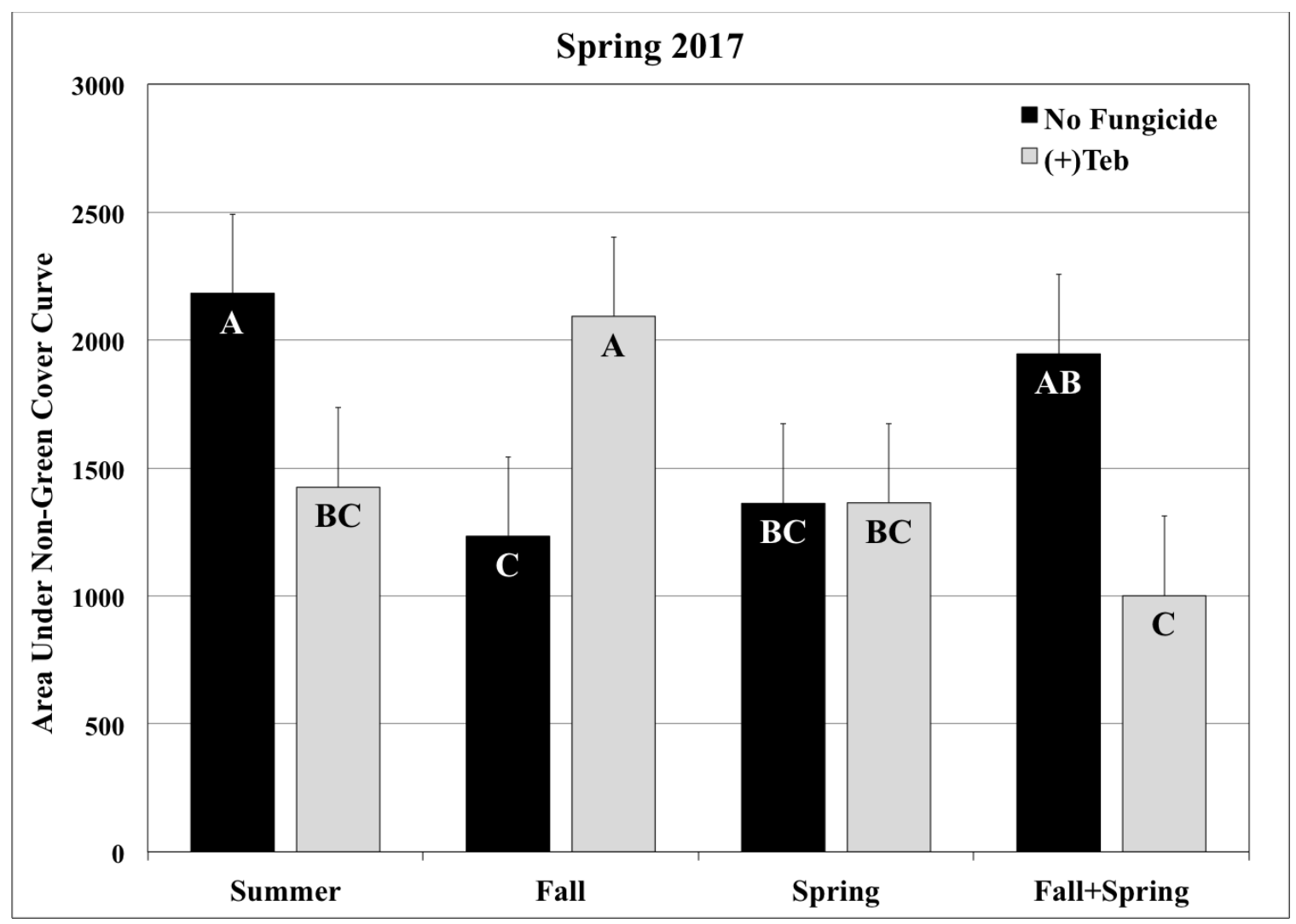

Figure 3.6 Effects of nitrogen application timing on non-green turf in Spring 2017. Means are averaged across all calcium nitrate, ammonium sulfate, and urea applications. AUNGCC represents the total non-green cover acquired through digital image analysis in Sigma Scan and calculated using the trapezoidal rule (Madden et al. 2007; Shaner and Finney 1977). Bars with the same letters are not significantly different from each other according to Fisher's protected LSD $(\alpha=0.05)$. Error bars represent the standard error of the mean. 


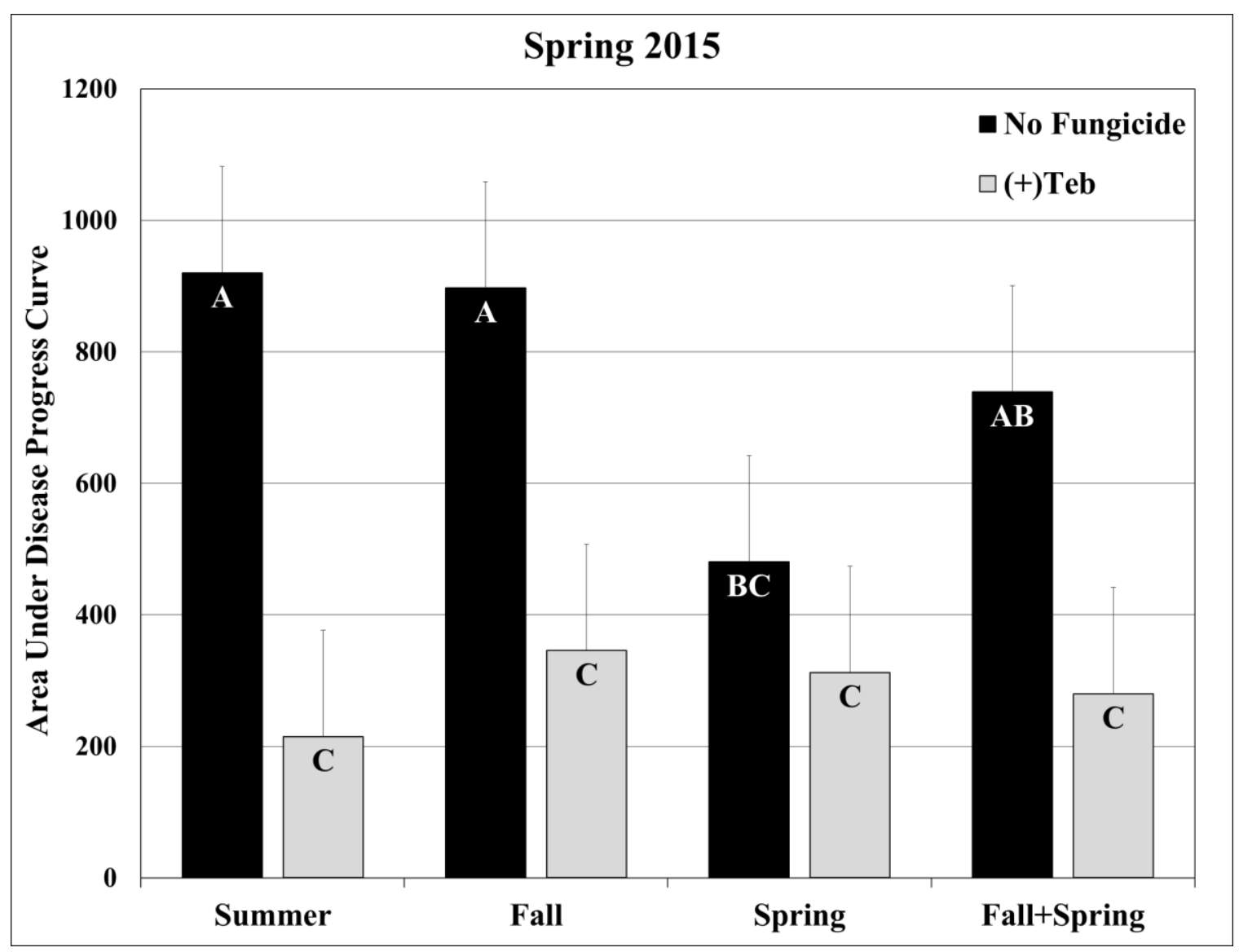

Figure 3.7 Effects of nitrogen application timing on visual large patch severity on zoysiagrass in Spring 2015. Means are averaged across all calcium nitrate, ammonium sulfate, and urea applications. AUDPC represents the total estimated visual disease severity calculated over a given time using the trapezoidal rule (Madden et al. 2007; Shaner and Finney 1977). Bars with the same letters are not significantly different from each other according to Fisher's protected LSD $(\alpha=0.05)$. Error bars represent the standard error of the mean. 


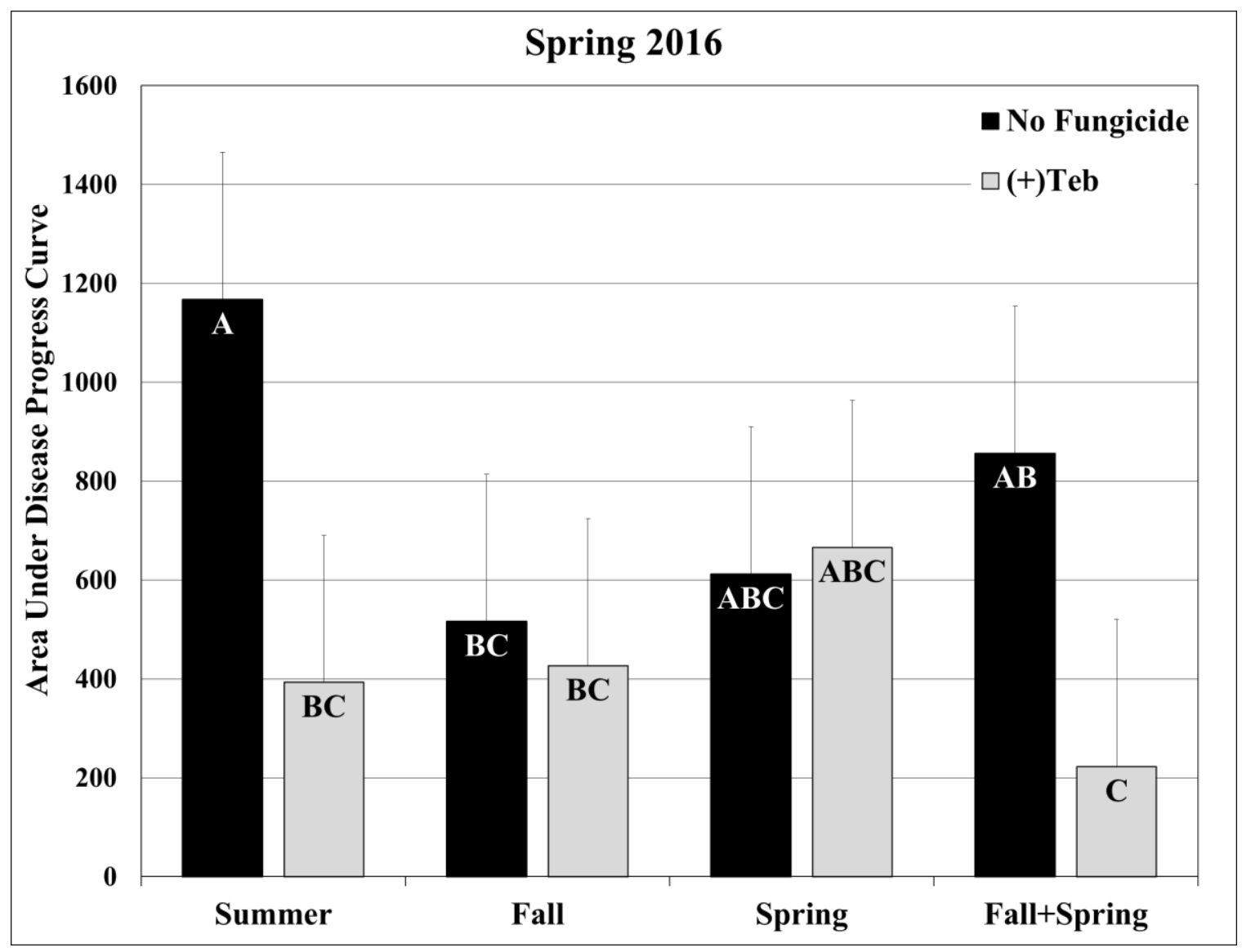

Figure 3.8 Effects of nitrogen application timing on visual large patch severity on zoysiagrass in Spring 2016. Means are averaged across all calcium nitrate, ammonium sulfate, and urea applications. AUDPC represents the total estimated visual disease severity calculated over a given time using the trapezoidal rule (Madden et al. 2007; Shaner and Finney 1977). Bars with the same letters are not significantly different from each other according to Fisher's protected LSD $(\alpha=0.05)$. Error bars represent the standard error of the mean. 


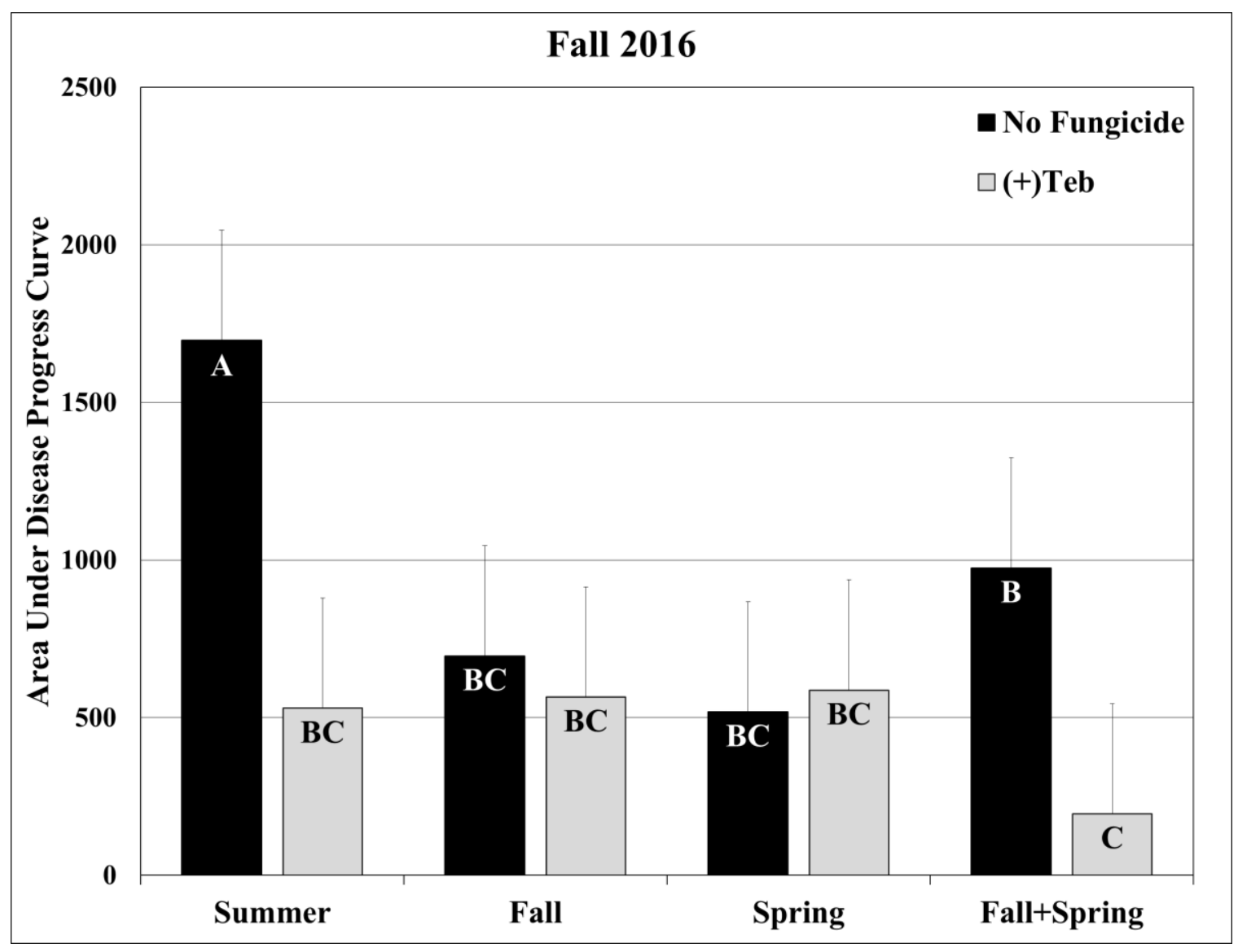

Figure 3.9 Effects of nitrogen application timing on visual large patch severity on zoysiagrass in Fall 2016. Means are averaged across all calcium nitrate, ammonium sulfate, and urea applications. AUDPC represents the total estimated visual disease severity calculated over a given time using the trapezoidal rule (Madden et al. 2007; Shaner and Finney 1977). Bars with the same letters are not significantly different from each other according to Fisher's protected LSD $(\alpha=0.05)$. Error bars represent the standard error of the mean. 


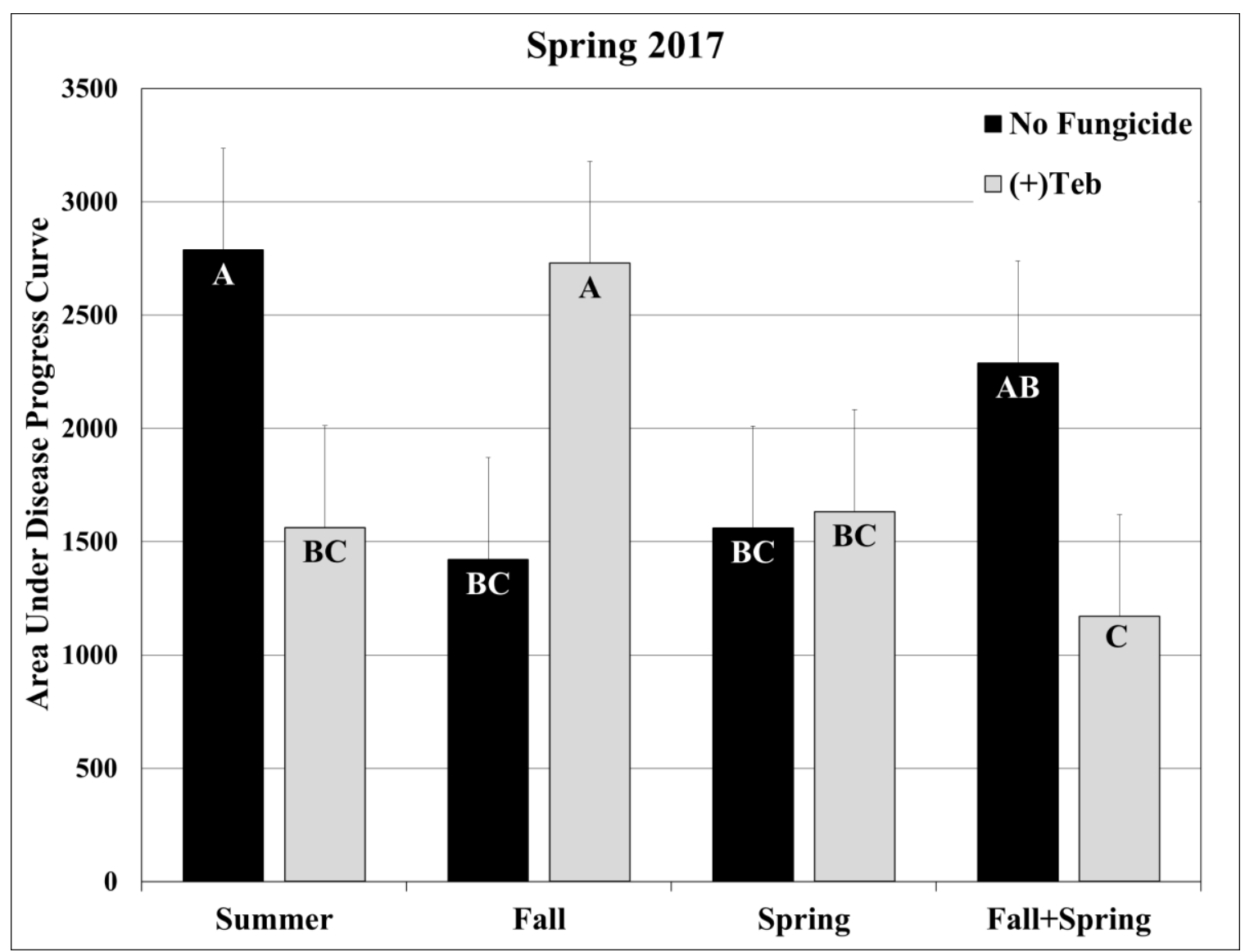

Figure 3.10 Effects of nitrogen application timing on visual large patch severity on zoysiagrass in Spring 2017. Means are averaged across all calcium nitrate, ammonium sulfate, and urea applications. AUDPC represents the total estimated visual disease severity calculated over a given time using the trapezoidal rule (Madden et al. 2007; Shaner and Finney 1977). Bars with the same letters are not significantly different from each other according to Fisher's protected LSD $(\alpha=0.05)$. Error bars represent the standard error of the mean. 